\title{
Asymmetric Damage Mechanism of Floor Roadway based on Stope Floor Zonal Damage Characteristics: A Case Study
}

\section{Hongbao Zhao}

China University of Mining and Technology Beijing Campus

Yihong Liu ( $D$ lyhcumtb@163.com )

China University of Mining and Technology Beijing Campus

Shaoqiang Liu

China University of Mining and Technology Beijing Campus

Wenhao Sun

China University of Mining and Technology Beijing Campus

\section{Research Article}

Keywords: residual pillar, floor, unloading, roadway, asymmetric damage

Posted Date: January 31st, 2022

DOI: https://doi.org/10.21203/rs.3.rs-1288572/v1

License: @ (i) This work is licensed under a Creative Commons Attribution 4.0 International License.

Read Full License 


\title{
Asymmetric Damage Mechanism of Floor Roadway based on Stope Floor Zonal
}

\section{Damage Characteristics: A Case Study}

\author{
Hongbao Zhao ${ }^{1,2}$, Yihong Liu ${ }^{1,2}$, Shaoqiang Liu ${ }^{1}$, Wenhao Sun ${ }^{1}$
}

1. School of energy and mining Engineering, China University of Mining \& Technology-Beijing, Beijing 100083, China

\section{State Key Laboratory of Mining Response and Disaster Prevention and Control in Deep Coal} Mines, Anhui University of Science and Technology, Huainan, Anhui 232001, China Corresponding author: Yihong Liu; E-mail: 1yhcumtb@163.com; Tel: +86 18811653059

\begin{abstract}
By means of field observation, theoretical analysis, numerical simulation etc., the zonal failure characteristics of stope floor and the asymmetric failure mechanism of floor roadway were studied. The study results showed that the floor roadway rib near the residual coal pillar has lower ultrasonic wave velocity than the other rib, with more developed fissures. The deflection is larger in the middle of the roadway roof and the tensile failure is the dominant one, and as a result, the ultrasonic wave velocity in the middle of the roadway roof is lower than that on both sides; under the advance abutment pressure, there was no large-scale failure in stope floor, while in the compaction stability stage, a large range of compressive shear failure was found in the residual pillar floor.

The mining-induced unloading causes a large tensile stress at the internal defects of the floor rock in the goaf, which leads to the goaf floor dominated by tensile failure; the numerical simulation results revealed that there is a spherical stress concentrated shell and spherical stress relief body in the goaf floor. The shape and range of tensile plastic zone of the goaf floor correspond to the spherical stress relief body, and the shape and range of shear failure zone of the floor correspond to the spherical stress concentrated shell; One side of the floor roadway is close to the rock mass with compressive shear damage and the other side close to the rock mass with unloadinginduced tensile damage, which is the main reason for the asymmetric failure of the roadway. According to the asymmetric failure mechanism of the floor roadway, asymmetric support measures are proposed for the roof and floor respectively.
\end{abstract}

Keywords: residual pillar; floor; unloading; roadway; asymmetric damage

\section{Introduction}

Occurrence and mining of close distance coal seams account for a large proportion in mining areas of China, such as Handan, Huozhou and Pingdingshan [1][2][3]. Downward mining is the main method of mining in the closed distance seam group. During the upper coal seam mining, the mining-induced stress will cause disturbance and damage to the floor strata, and after the upper coal seam mining, there will be a large number of coal pillars left, which will cause more serious stress concentration on the floor strata. During the lower coal seam mining, the 
roadway is set in the rock strata disturbed and damaged by the upper coal mining-induced stress, so it has poor integrity. In addition, the roadway is also affected by the concentrated stress of the overlying residual coal pillar, which leads to the complex failure mechanism of the lower coal seam mining roadway. Fig. 4 shows the asymmetric failure characteristics of the lower coal seam mining roadway.

Many scholars have conducted a large number of studies on the failure characteristics of the floor rocks of the goaf. Some scholars, starting from the geological conditions of coal-bearing and based on the statics theory, studied the influence of the thickness and strength of coal seam floor on the stability of the stope floor, and predicted the failure range of the floor [4][5][6]. For example, C. F. Santos and Z.T. Bieniawski et al. [7] analyzed the carrying capacity of stope floor strata based on the improved Hoek-Brown strength criterion and the concept of critical energy release point; C. Faria Santos and Z.T. Bieniawski et al. [8] studied the failure mechanism of stope floor from the perspective of rock mechanics; and V. Mironenko and F. Strelsky et al. [9] proposed a method to reduce the range of floor failure based on the mining failure characteristics of stope floor and the properties of floor strata. In recent years, Chinese scholars have conducted systematic studies on the failure characteristics of stope floor. For instance, Liu Tianquan [10] proposed the "three belts in floor" theory of the response of surrounding rock to mining, i.e., the stope floor can be divided into burst belt, micro fissure belt and micro-variation belt of stress; Wang Lianguo et al. [11] analyzed the stress distribution and failure law of the floor based on the theory of elastic-plastic mechanics; Luo Feng et al. [12] obtained the space-time difference characteristics of coal seam group floor strain under the condition of primary and secondary mining during the downward mining of close distance coal seams using similarity simulation and numerical simulation; Guo Wenbing [13][14] conducted a photoelastic simulation study on the surrounding rock of the stope, and analyzed the interaction relationship and stress distribution of coal seam groups under mining conditions; Fang Xinqiu [15], using field measurement, theoretical analysis, numerical simulation and other research methods, analyzed the instability mechanism of the lower coal seam mining roadway under the influence of the residual coal pillar in the upper coal seam goaf and the dynamic pressure of the coal seam adjacent to working face. Tu Shihao et al. [16][17] studied the roof structure and control of lower coal seam stope of close distance coal seams as well as the law of roadway rock pressure behaviors. They believed that the roadway stability could be effectively increased through the reasonable design of roadway position and coal pillar width; and Lu Shiliang et al. [18] studied the reasonable vertical spacing between mining roadway and upper coal seam.

During the coal mining, with the advance of the working face, the stope floor goes through the stage of advance abutment pressure disturbance of the working face, the stage of floor pressure relief and the stage of goaf compaction stability [19][20]. During the stage of floor pressure relief, there is a differential rebound deformation in the floor and even tensile stress occurs, which weakens the floor stability. For deep mine surrounding rock with high stress, the unloading effect of the floor is more obvious, and the width of the unloading-induced tensile crack is often larger than that of the compressive shear crack, which has a stronger degradation effect on the floor [21][22][23]. However, the influence of unloading effect of coal seam mining on the failure characteristics of floor is rarely considered in the existing studies. Therefore, in this paper, the zonal failure characteristics of stope floor were studied through field observation, theoretical analysis, numerical simulation etc., and the asymmetric failure mechanism of the lower coal seam roadway was analyzed based on the zonal failure characteristics of floor rock mass.

\section{Case study}

\subsection{Mining and geological conditions}

The Huipodi Coal Mine is located in Linfen City, Shanxi Province, China. There are two layers of minable coal seams - No. 10 and No. 11 in this mine, both of which are nearly horizontal coal seams, with the average spacing between coal seams of $7 \mathrm{~m}$, and the average buried depth of about $550 \mathrm{~m}$. The Stratigraphic column of the study area is shown in Fig. 1. There is no large fault structure nearby, and the occurrence of coal seam is stable. Downward mining is mainly adopted here. The longwall mining method was used in No. 10 coal seam, with the caving method for roof control, the mining height of $\mathrm{h}=3 \mathrm{~m}$, and coal pillar width of about $30 \mathrm{~m}$. No. 10-103 and No. 10-102 are the two adjacent gobs of No. 10 coal seam. No. 11-1021 roadway is the haulage roadway of No. 11- 
102 coal mining face of No. 11 coal seam, and the horizontal dislocation distance between No. 11-1021 roadway and the residual coal pillar of the upper coal seam is $10 \mathrm{~m}$. The width of the residual coal pillar is about $30 \mathrm{~m}$. The positional relationship between the roadway and the residual coal pillar is shown in Figure 2.

\begin{tabular}{|c|c|c|}
\hline - & Thickness(m) & Lithology \\
\hline & 8 & Mudstone \\
\hline & 8 & Siltstone \\
\hline 111 & 9 & $\mathrm{~K}_{2}$ limestone \\
\hline 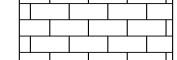 & 3 & Mudstone \\
\hline & 3.4 & $10^{\#}$ Coal seam \\
\hline & 3 & Siltstone \\
\hline 2 & 4 & Mudstone \\
\hline & 3.5 & $11^{\#}$ Coal seam \\
\hline & 4 & Mudstone \\
\hline+4 & 2.2 & Siltstone \\
\hline 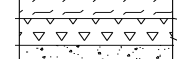 & 3.4 & Aluminum mudstone \\
\hline & 2 & Quartz sandstone \\
\hline $2+2$ & 10 & Siltstone \\
\hline
\end{tabular}

Fig.1 Stratigraphic column at the study site

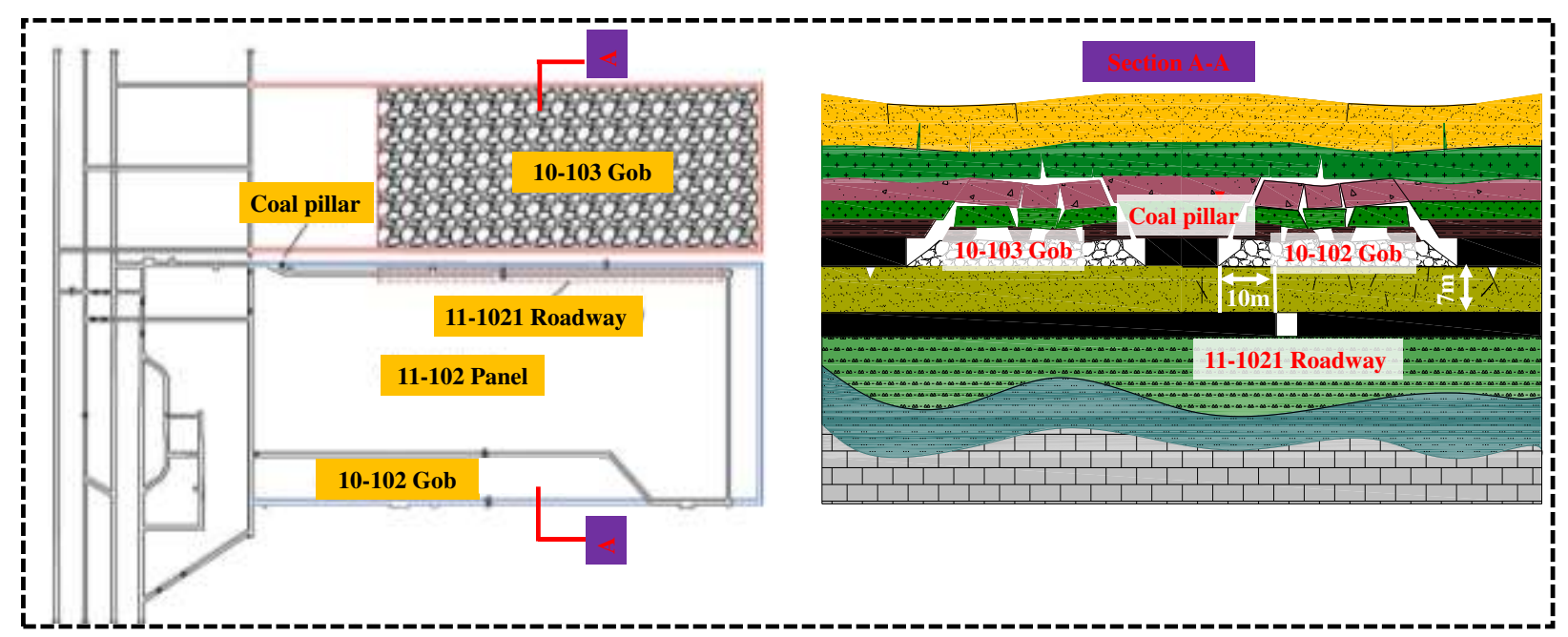

Fig.2 Position relationship between 11-1021 roadway and goaf

In the process of No. 11-1021 roadway excavation, the mining in both No. 10-102 and No. 10-103 working faces was completed. No. 11-1021 roadway has a rectangular cross-section, with a net width of $4.6 \mathrm{~m}$ and a net height of $3.3 \mathrm{~m}$. The combined support form based on anchor net beam and anchor cable was adopted, with the anchor rod with a diameter of $20 \mathrm{~mm}$ and a length of $2000 \mathrm{~mm}$ for the roof and rib. The row spacing of anchor rods in the roof and rib was $800 \mathrm{~mm} \times 800 \mathrm{~mm}$ and $800 \mathrm{~mm} \times 900 \mathrm{~mm}$, respectively. The anchor cable with a radius of 18.9 was used to strengthen the support for the roof, with the cable length of $5500 \mathrm{~mm}$, and the row spacing between the cables of $2400 \mathrm{~mm} \times 1600 \mathrm{~mm}$. Due to the poor integrity of the surrounding rock of the roadway, each row of the serious deformation area of the roadway was equipped with 3 pillars with the top beams, with a row spacing of $2000 \mathrm{~mm} \times 1800 \mathrm{~mm}$. The cross-section diagram of roadway support is shown in Fig. 3 . 


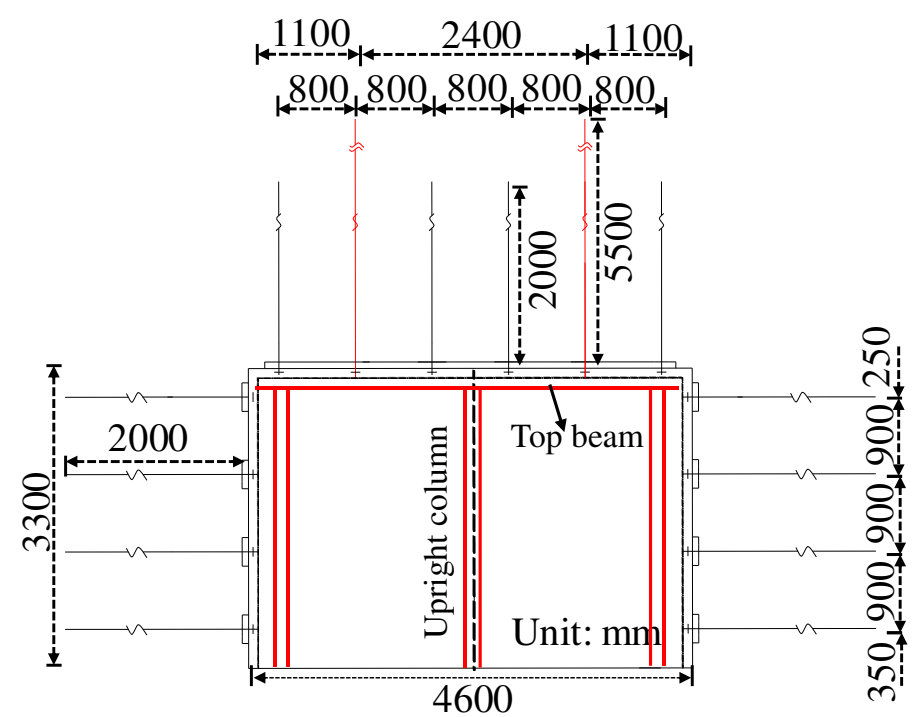

Fig.3 11-1021 roadway support section diagram

In the process of upper coal seam mining, strong mining-induced damage was caused to No. 11 coal seam, and the residual coal pillar led to stress concentration to the floor after the working face mining. Under the action of the upper coal seam mining-induced unloading and the concentrated stress of residual pillar, there was severe asymmetric deformation and failure after No. 11-1021 roadway excavation: the damage to the roof near the residual coal pillar side and to the rib was obviously more serious than that to the other side; the W-type steel band was seriously bent and deformed; and there was local roof collapse and leakage, forming a net bag. As for the floor, no support and reinforcement measures were taken here, and since the immediate bottom of the roadway was aluminum mudstone, serious asymmetric floor heaving occurred in the roadway floor, in which the floor heaving on the side far away from the residual coal pillar was much larger than that on the other side, as shown in Fig. 4.

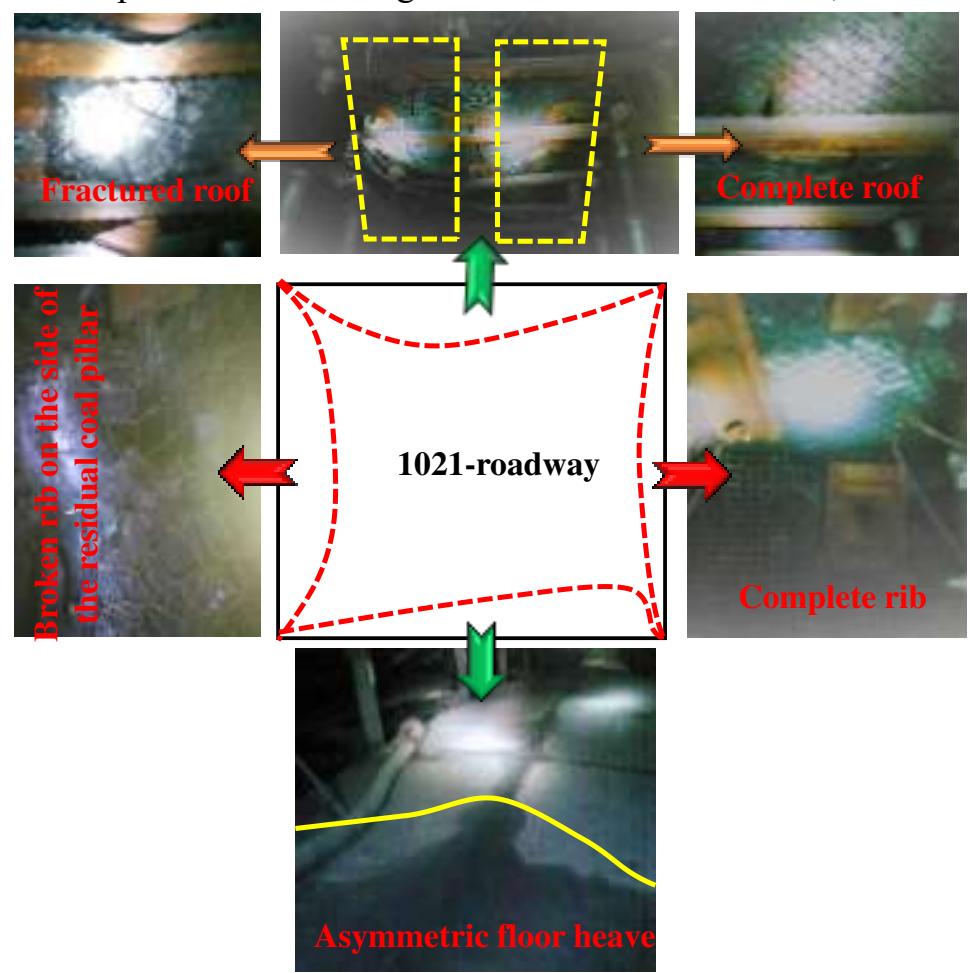

Fig.4 11-1021 Roadway surrounding rock deformation characteristics

\subsection{Damage characteristics observed of roadway surrounding rock}

Under the influence of mining disturbance, fissure development in the roadway surrounding rock is the fundamental reason for the expansion and deformation of the surrounding rock. However, the fissure involves 
parameters such as density, size and dip angle, so it is difficult to directly measure the fissure in situ. Therefore, it is necessary to find the mechanical parameters that can reflect the fracture development degree to characterize the damage degree of surrounding rock. Many scholars have studied the propagation characteristics of ultrasonic wave in coal-rock materials, and found that the cracks in rock mass hindered the propagation of ultrasonic wave, and the ultrasonic wave is reflected and transmitted on the fissure surface, resulting in the decrease of wave velocity and signal strength. In addition, experiments showed that the relationship between fissure density in rock mass and Poisson's ratio satisfies [24]:

$$
p=\frac{45}{8} \frac{\mu_{i}-\mu}{\left(1+\mu_{i}\right)\left[10 \mu_{i}-\mu\left(1+8 \mu_{i}\right)\right]}
$$

Where, $\mathrm{p}$ is the fracture density in rock mass $\left(\mathrm{bar} / \mathrm{m}^{3}\right), \boldsymbol{\mu}_{i}$ represents the Poisson's ratio of intact rock mass, and $\mu$ is the Poisson's ratio of fractured rock mass.

The relationship between ultrasonic wave velocity in rock mass and material parameters is as follows [25][26]:

$$
v=\sqrt{E /[2 \rho(1+\mu)]}
$$

Where, $v$ indicates the propagation velocity of ultrasonic wave in rock mass $(\mathrm{km} / \mathrm{s})$, E is the elastic modulus (GPa), and $\rho$ stands for the density $\left(\mathrm{kg} / \mathrm{m}^{3}\right)$.

It is assumed that the Poisson's ratio, density and elastic modulus of intact rock mass are $0.15,1400 \mathrm{~kg} / \mathrm{m} 3$ and $12 \mathrm{GPa}$ respectively. The relationship between ultrasonic wave velocity and fracture density can be obtained from Equations (1) and (2), as shown in Fig. 5. Namely, the ultrasonic wave velocity decreases with the increase of fracture density, indicating that the smaller the ultrasonic propagation velocity in the surrounding rock, the higher the degree of fracture development.

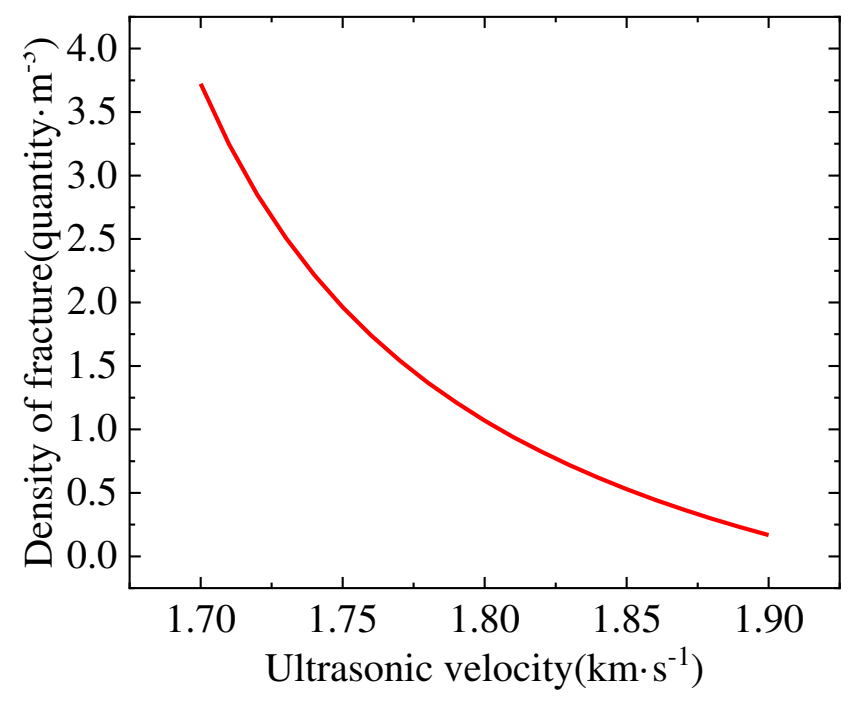

Fig.5 The relationship between crack density and ultrasonic velocity

As the working face of 11\# coal seam has not been mined, roadway 11-1021 is not affected by mining temporarily. To explore the asymmetric deformation mechanism of No. 11-1021 roadway, the ultrasonic distribution characteristics of roadway surrounding rock were monitored on site. Three measuring stations are arranged in roadway 11-1021, with a spacing of $15 \mathrm{~m}$. As shown in Figure 6, 5 groups of boreholes are arranged at each monitoring station, and two boreholes are arranged in parallel along the axis of the roadway, a total of 10 boreholes. The distance between the two boreholes in the group is $0.2 \mathrm{~m}$, and the transmitting probe and receiving probe of ultrasonic signal are installed respectively, with the borehole diameter of $32 \mathrm{~mm}$. Before the test, inject an appropriate amount of coupling agent into the bottom of the drilling hole to ensure that the probe is in close contact with the hole wall. 


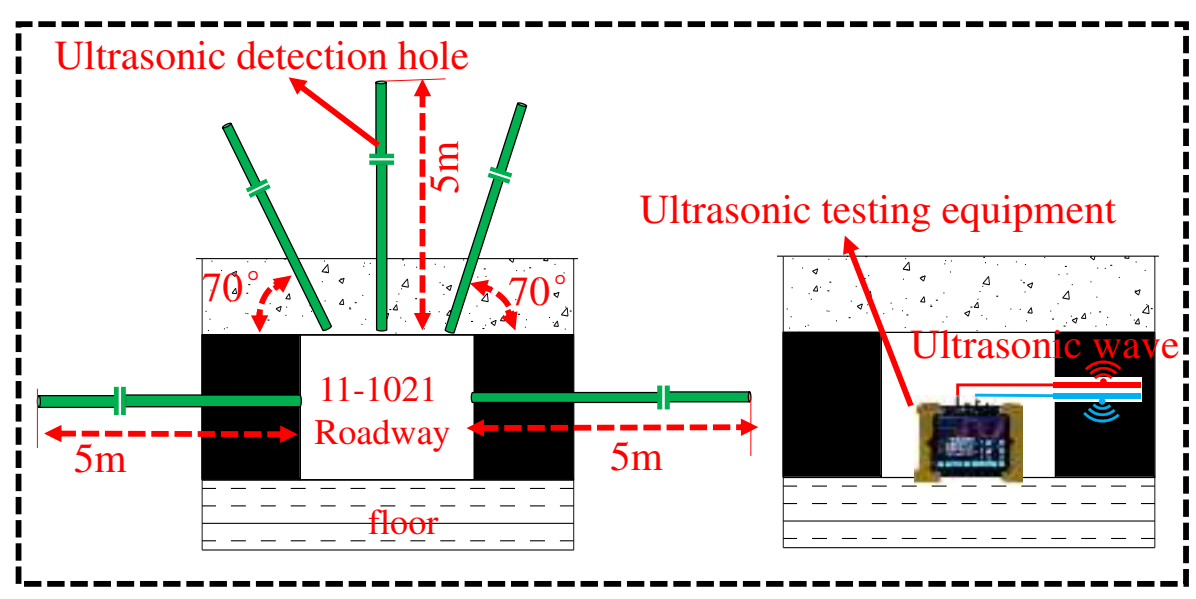

Fig.6 Ultrasonic detection hole layout diagram

The ultrasonic monitoring results of roadway surrounding rock are shown in Figure 7. The ultrasonic velocity in surrounding rock is between $0.3 \sim 0.8 \mathrm{~km} / \mathrm{s}$, and the integrity of surrounding rock is poor. The measurement results of the three stations all showed that the ultrasonic wave velocity of the roadway rib near the residual coal pillar is lower than that of the other rib, mainly because the roadway rib near the residual coal pillar is more affected by the concentrated stress of the coal pillar, which leads to the increased degree of crushing and higher degree of fracture development of the roadway rib after excavation. The ultrasonic wave velocity in the middle of the roadway roof is lower than that in the two sides. This is because after excavation of the roadway, a beam structure with fixed supports on both sides is formed in the roof, and when the roof is bent and deformed, the two sides are dominated by extrusion failure, while the middle part is marked by larger deflection and dominated by tensile failure. Since the tensile crack is wider, thus imposing a larger hindering effect on ultrasonic propagation, therefore, the ultrasonic wave velocity in the middle of the roadway roof is lower than that on the two sides.
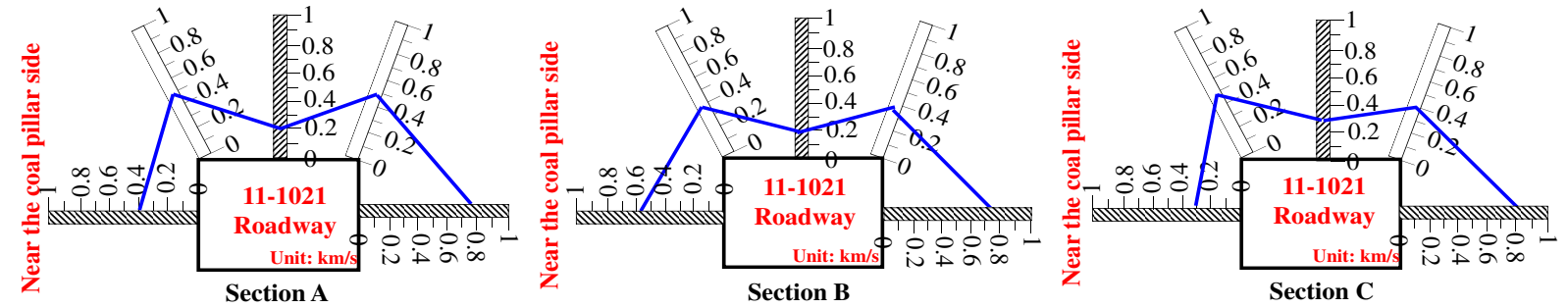

Fig.7 Distribution of Ultrasonic Velocity of Roadway Surrounding Rock

\section{Compression-shear failure characteristics of stope floor}

The damage characteristics of floor under upper coal seam mining disturbance largely determine the integrity of surrounding rock of No. 11-1021 roadway. Therefore, it is necessary to analyze the damage characteristics of the floor after upper coal seam mining. During the upper coal seam mining, with the advance of the working face, the stope floor goes through the stage of advance abutment pressure disturbance of the working face, the stage of floor pressure relief and the stage of gob compaction stability. The stage of advance abutment pressure disturbance refers to the stress state of the floor in the section where the peak abutment pressure is located in front of the working face; the stage of gob compaction stability refers to the stress state of the floor after the gob is compacted and stabilized; and the stage of floor pressure relief refers to the stress relief process from the stage of abutment pressure disturbance to the stage of compaction stability. Based on Fig. 2 and classical mine pressure theory [27], a mechanical model of the floor as shown in Fig. 8 was obtained by linear simplified processing of the abutment pressure of coal pillar, the abutment pressure of the outer side of gob and the force of roof caving rock on the floor. In the figure, 2D is the width of residual coal pillar; $w_{1}$ and $w_{2}$ represent the width of plastic bearing zone; $n$ stands for the width of elastic region; and $K_{1}$ and $K_{2}$ are stress concentration factors. 


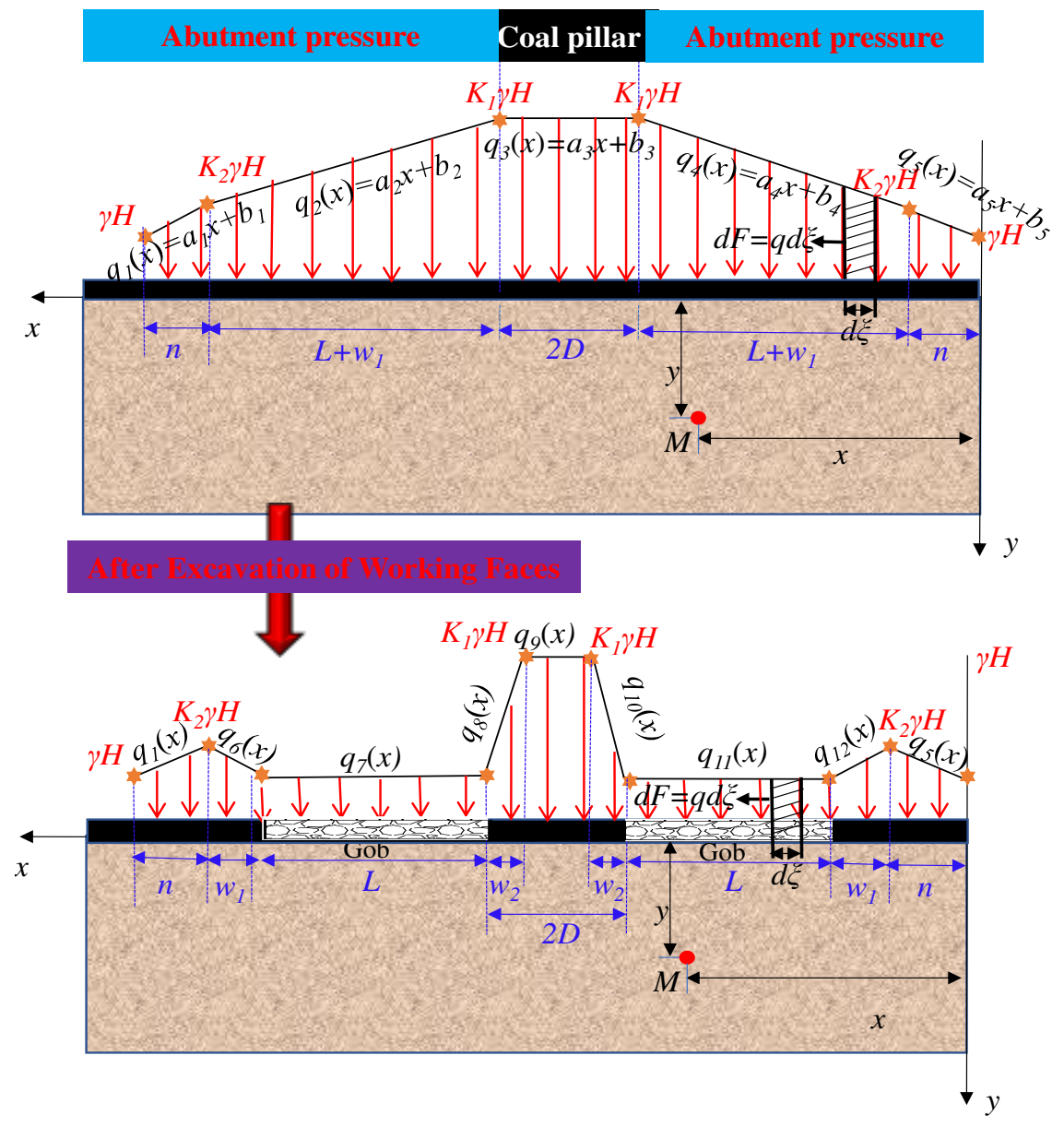

Fig.8 Mechanics model of stope floor

Based on the mechanical model in Fig. 8, the distribution load intensity $q_{k}$ of the overlying rock is expressed as follows [28][29]:

$$
\left.\begin{array}{l}
q_{1}(x)=\frac{\gamma\left(H-K_{2} H\right)}{n}(x-n-w-2 L-2 D)+K_{2} \gamma H \\
q_{2}(x)=\frac{\gamma H\left(K_{2}-K_{1}\right)}{L+w_{2}+w_{1}}\left(x-n-w_{1}-L-2 D+w_{2}\right)+K_{1} \gamma H \\
q_{3}(x)=K_{1} \gamma H \\
q_{4}(x)=\frac{\gamma H\left(K_{1}-K_{2}\right)}{L+w_{1}+w_{2}}(x-n)+K_{2} \gamma H \\
q_{5}(x)=\frac{\gamma H\left(K_{2}-1\right)}{n} x+\gamma H \\
q_{6}(x)=\frac{\gamma\left(K_{3} H-H\right)}{w_{1}}\left(x-n-w_{1}-2 L-2 D-w_{1}\right)+K_{2} \gamma H \\
q_{7}(x)=\gamma H_{m} \\
q_{8}(x)=\frac{\gamma\left(H-K_{1} H\right)}{w_{2}}\left(x-n-w_{1}-L-2 D-w_{2}\right)+K_{1} \gamma H \\
q_{9}(x)=K_{1} \gamma H \\
q_{10}(x)=\frac{\gamma\left(K_{1} H-H\right)}{w_{2}}\left(x-n-w_{1}-L-w_{2}\right)+K_{1} \gamma H \\
q_{11}(x)=\gamma H_{m} \\
q_{12}(x)=\frac{\gamma\left(H-K_{2} H\right)}{w_{1}}(x-n)+K_{2} \gamma H
\end{array}\right\}
$$


According to the relevant theories of elasticity and the integral principle, the stress caused by the load $\left(q_{k}\right)$ acting on the floor at any point $M(x, y)$ can be obtained as follows [30]:

$$
\left.\begin{array}{c}
\sigma_{x}=\sum_{k=1}^{n} \int_{x_{k}}^{x_{k+1}} \frac{2 q_{k}(\xi)}{\pi} \frac{\left(x-\xi^{2}\right) y}{\left[\left(x-\xi^{2}\right)+y^{2}\right]^{2}} d \xi \\
\sigma_{y}=\sum_{k=1}^{n} \int_{x_{k}}^{x_{k+1}} \frac{2 q_{k}(\xi)}{\pi} \frac{y^{3}}{\left[\left(x-\xi^{2}\right)+y^{2}\right]^{2}} d \xi \\
\tau_{x y}=\sum_{k=1}^{n} \int_{x_{k}}^{x_{k+1}} \frac{2 q_{k}(\xi)}{\pi} \frac{y^{2}(x-\xi)}{\left[\left(x-\xi^{2}\right)+y^{2}\right]^{2}} d \xi
\end{array}\right\}
$$

The maximum and minimum principal stress can be calculated as follows:

$$
\left.\begin{array}{l}
\sigma_{1} \\
\sigma_{3}
\end{array}\right\}=\frac{\sigma_{x}+\sigma_{y}}{2} \pm \sqrt{\left(\frac{\sigma_{x}-\sigma_{y}}{2}\right)^{2}+\tau_{x y}^{2}} .
$$

Mohr-Coulomb criterion has fewer parameters, and is simple to apply and easy to understand. Combined with Figure 9, the Mohr-Coulomb criterion is expressed as follows:

$$
F(\sigma)=\tau_{m}-\tau_{u}=\left(\sigma_{m}+c \cot \varphi\right) \sin \varphi-\frac{\sigma_{1}-\sigma_{3}}{2} \leq 0
$$

Where, $\boldsymbol{C}$ is the cohesion, Mpa; $\varphi$ indicates the internal friction angle, $\left(^{\circ}\right) ; \sigma_{m}=\left(\sigma_{1}+\sigma_{3}\right) / 2 ; \tau_{m}$ represents the vertical distance between the center of Mohr's circle and the envelope; $\tau_{u}$ is the maximum shear stress of surrounding rock (Mohr's circle radius). When the maximum shear stress $\tau_{u}$ is smaller than $\tau_{m}$, the surrounding rock is in the elastic state; when $\tau_{u}$ is equal to $\tau_{m}$, the surrounding rock is in the limit equilibrium state; and when $\tau_{u}$ is greater than $\tau_{m}$, the surrounding rock is in a state of plastic stress, and the failure area of the unit is:

$$
\left.\begin{array}{l}
\frac{\pi}{4}+\frac{\varphi}{2}-\frac{\delta}{2} \leq \beta \leq \frac{\pi}{4}+\frac{\varphi}{2}+\frac{\delta}{2} \\
\delta=\arccos \frac{2\left(\sigma_{m}+c \cot \varphi\right) \sin \varphi}{\sigma_{1}-\sigma_{3}}
\end{array}\right\}
$$

Where, $\beta$ is the angle between the rock fracture direction and the maximum principal stress; $\delta$ represents the angle between the yield point of critical failure boundary of rock mass and that of the ultimate equilibrium state. The smaller $F(\sigma)$ value is, the larger $\beta$ range is, and the stronger the compressive shear failure of rock mass is.

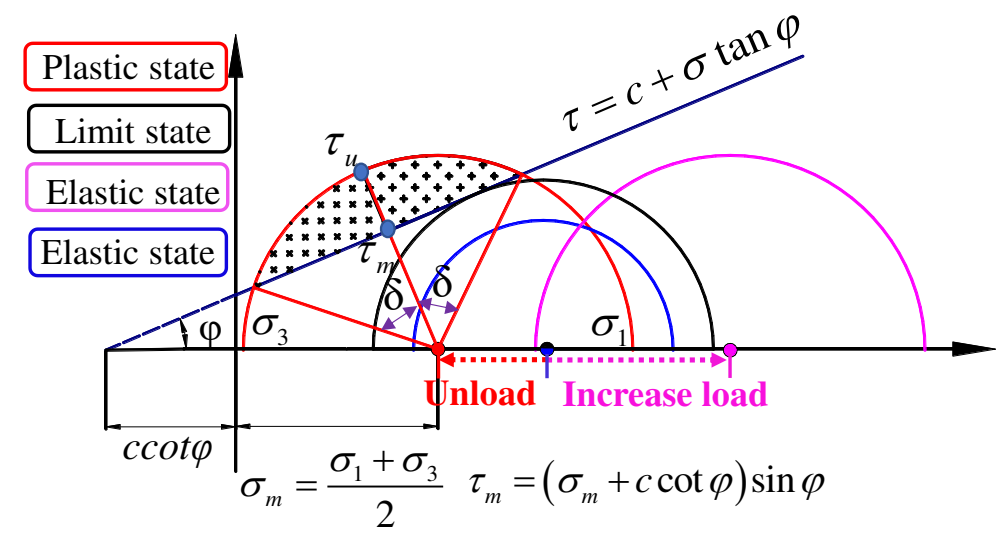

Fig.9 Mechanical mechanism of rock mass failure As can be seen from Fig. 9, the radius of Mohr's circle and the variation range of principal stress (the position 
of the center of Mohr's circle) determine whether the rock mass is unstable. Thus, the rock mass may change from the limit equilibrium state to the stable state under loading, and from the elastic state to the unstable state under unloading.

The geological data of East No.1 Mining Area of Huipodi Coal Mine, observation data of mine pressure during mining and the numerical simulation results were used as reference to select the theoretical model calculation parameters, as shown in Table 1. According to Fig. 8 and Equations (3) (6), the distribution characteristics of floor plastic zones in the stage of abutment pressure disturbance and the stage of gob compaction stability were obtained, as shown in Fig. 10. According to the theoretical calculation results, there was no floor failure in the stage of abutment pressure disturbance in front of the working face. This is because under the advance abutment pressure, the maximum principal stress and minimum principal stress of stope floor were in the state of high value, and as can be seen from Fig. 9, when $\sigma_{1}$ and $\sigma_{3}$ are large and close in value, the radius of Mohr's circle becomes smaller, thus $\tau_{u}$ becoming smaller, and therefore, the surrounding rock is not prone to damage. In the stage of compaction stability, since the floor has undergone unloading, there is a large difference between the maximum and minimum principal stress relief amplitudes of the residual coal pillar floor, which leads to the increase of Mohr's circle radius and thus a large range of compressive shear failure of residual coal pillar floor, while there is a small difference between the maximum and minimum principal stress relief amplitudes of the outer floor of the stope, resulting in a small range of compressive shear failure of the floor; and the difference in principal stress relief amplitude of the gob floor is the smallest, so the rock mass is not damaged, and the failure pattern of the floor is symmetrically distributed around the center of the pillar.

Tab.1 Calculation model parameters

\begin{tabular}{ccccccccccc}
\hline $\mathrm{H} / \mathrm{m}$ & $\mathrm{H}_{\mathrm{M}} / \mathrm{m}$ & $\mathrm{L} / \mathrm{m}$ & $\mathrm{C} / \mathrm{MPa}$ & $\boldsymbol{\varphi} /\left(^{\circ}\right)$ & $\gamma^{/\left(\mathrm{KN} \cdot \mathrm{m}^{-3}\right)}$ & $\mathrm{K}_{1}$ & $\mathrm{~K}_{2}$ & $\mathrm{w}_{1}$ & $\mathrm{w}_{2}$ & $\mathrm{n}$ \\
\hline 550 & 30 & 100 & 2.1 & 21 & 27 & 3.2 & 2.5 & 8 & 6 & 13 \\
\hline
\end{tabular}

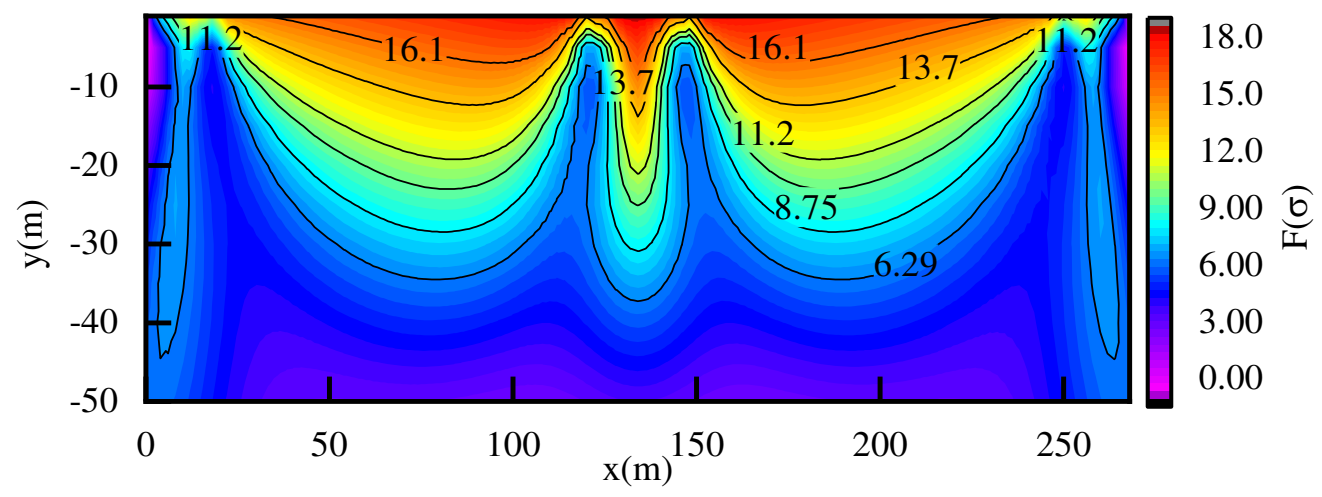

(a) the stage of abutment pressure disturbance

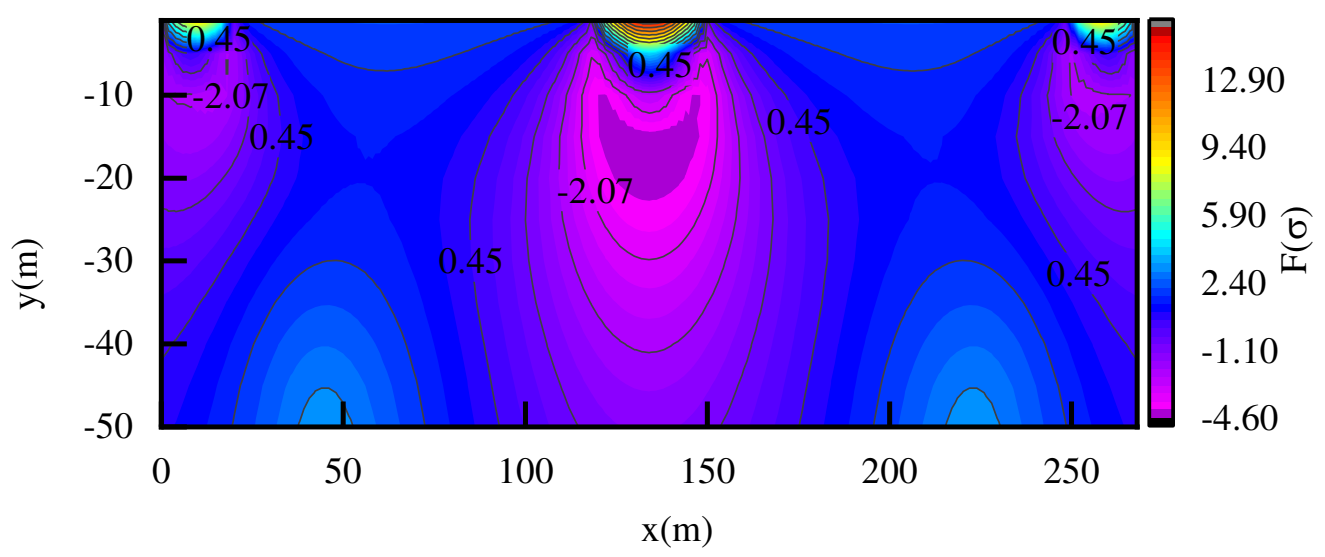

(b) the stage of gob compaction stability 
Fig.10 Theoretical failure mode of stope floor

\section{Unloading damage characteristics of floor}

\subsection{Unloading damage mechanism of floor}

Assuming that the stress action time is long enough before the working face passes through the floor, the stress concentrated at the defect in the floor has been completely relaxed. The working face passing through the floor is equivalent to unloading the floor in the vertical direction. It is assumed that the stress in the $\mathrm{X}$ and $\mathrm{Y}$ directions remains unchanged, the unloading is linear in the $\mathrm{Z}$ direction, as shown in Fig. 11.

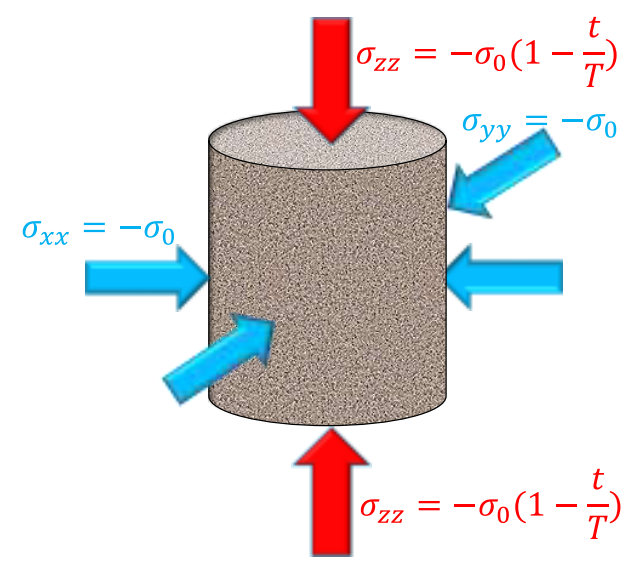

Fig.11 Schematic diagram of unloading

When unloading, the stress meets:

$$
\left.\begin{array}{l}
\sigma_{x x}=\sigma_{y y}=-\sigma_{0} \\
\sigma_{z z}=-\sigma_{0}\left(1-\frac{t}{T}\right)
\end{array}\right\}
$$

Where, $\mathrm{T}$ is the total unloading time.

Stress concentration occurs at the defects of floor, and even for uniform deformation on average, uneven stress field may be generated. The local stress at the internal defects of floor is composed of two parts: the elastic stress following Hooke's law, which is uniformly distributed in the region; and the additional stress $\sigma_{z z}^{*}$ caused by defects. $\sigma_{z z}^{l o c}$ represents the local stress of floor, then:

$$
\sigma_{z z}^{l o c}=\sigma_{z z}^{e}+\sigma_{z z}^{*}
$$

According to Maxwell model, the evolution equation of stress concentration at the defect is [31]:

$$
\frac{d \sigma_{z z}^{*}}{d t}=K \rho c_{s}^{2} \&-\eta \frac{\sigma_{z z}^{*}}{l}
$$

Thereinto,

$$
\rho c_{s}^{2}=\frac{E}{2(1+v)}
$$

Where, $\&=\sigma_{0} / 3 \rho c_{s}^{2} T$ is the variation rate of deviatoric strain with time; $K$ represents the stress concentration factor on the defect; $\rho$ is the density of the medium; $c_{s}$ indicates the velocity of shear wave; $\rho c_{s}^{2}$ is dynamic shear modulus; $\eta$ is the relaxation rate of additional stress; and $E$ and $v$ are Young's modulus and Poisson's ratio, respectively.

Substitute $\left.\sigma_{z z}^{*}\right|_{t=0}=0$ as the initial conditions into Equation (10) to obtain: 


$$
\sigma_{z z}^{*}=\frac{K \sigma_{0} l}{3 T \eta}\left(1-\mathrm{e}^{-\frac{\eta}{l} t}\right)
$$

According to Equation (12), the unloading effect induced by the working face passing through the floor will cause tensile stress at the internal defects of the floor. The tensile stress generated at the defect is parallel to the unloading direction, and the magnitude of the tensile stress is proportional to the initial stress. Due to $\sigma_{z z}^{e} \approx \sigma_{z z}(t)$, therefore,

$$
\sigma_{z z}^{l o c}=\sigma_{z z}^{e}+\sigma_{z z}^{*} \approx \sigma_{z z}(t)+\sigma_{z z}^{*}
$$

Substituting Equations (8) and (12) into Equation (13), we can get:

$$
\sigma_{z z}^{l o c}=\frac{K \sigma_{0} l}{3 T \eta}\left(1-\mathrm{e}^{-\frac{\eta}{l} t}\right)-\sigma_{0}\left(1-\frac{t}{T}\right)
$$

The conditions of rock mass failure at the defect are as follows:

$$
\sigma_{z z}^{l o c}=\sigma_{t}
$$

Where, $\sigma_{t}$ is the tensile strength of rock mass.

Assuming that the unloading stress of rock mass is

$$
\Delta \sigma_{z z}=\sigma_{z z}(t)-\left(-\sigma_{0}\right)=\sigma_{0} \frac{t}{T}
$$

$\xi$ is used to indicate the stress unloading amount, then:

$$
\xi=\left|\frac{\Delta \sigma_{z z}}{-\sigma_{0}}\right|=\frac{t}{T}
$$

According to Equation (17), the relationship between unloading stress $\sigma_{z z}$, additional stress $\sigma_{z z}^{*}$ at the defect and local stress $\sigma_{z z}^{l o c}$ and stress unloading amount can be obtained:

$$
\left.\begin{array}{l}
\sigma_{z z}=-\sigma_{0}(1-\xi) \\
\sigma_{z z}^{*}=\frac{K \sigma_{0} l}{3 T \eta}\left(1-\mathrm{e}^{-\frac{\eta \xi T}{l}}\right) \\
\sigma_{z z}^{l o c}=\frac{K \sigma_{0} l}{3 T \eta}\left(1-\mathrm{e}^{-\frac{\eta \xi T}{l}}\right)-\sigma_{0}(1-\xi)
\end{array}\right\}
$$

The stress state of floor defects in the unloading process is shown in Fig. 12. When $\xi=0$, the local stress at the defect is $-\sigma_{0}$. With the increase of the stress unloading amount, the additional stress $\sigma_{z z}^{*}$ gradually increases while the local stress gradually decreases; when the stress unloading amount exceeds $\xi_{a}$, the local stress turns into tensile stress; and when the stress unloading amount reaches $\xi_{b}$, it exceeds the tensile strength of floor, and the failure occurs at the floor defect. If the initial stress is relatively small, $\sigma_{z z}^{l o c}$ cannot reach the tensile strength of the floor, and the rock will not be damaged. 


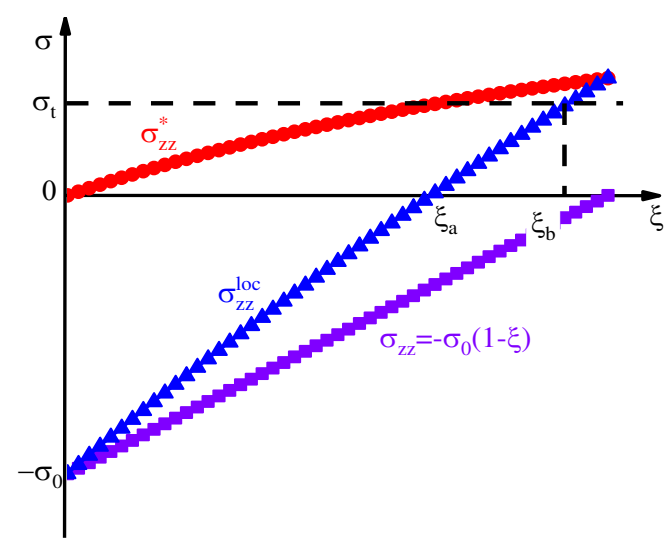

Fig.12 Unloading stress state of floor

Let the rock mass parameters $K=2, l=1 \times 10^{-6} \mathrm{~m}, \eta=2 \times 10^{-8} \mathrm{~m} / \mathrm{s}$ and $\sigma_{0}=50 \mathrm{MPa}$ to get the relationship between local stress and additional stress with unloading time and stress unloading amount, as shown in Fig. 13. The unloading time $\mathrm{T}$ determines the unloading rate, and the smaller the $\mathrm{T}$, the larger the unloading speed is. As can be seen from Fig. 13, the faster the unloading speed is, the greater the tensile stress at the defect will be, which will easily lead to the failure at the defect of the floor. When the unloading speed is small, the additional stress at the defect is small, and the floor is not prone to unloading failure. Therefore, in practice, slowing down the advancing speed of working face is beneficial to the stability of stope floor.

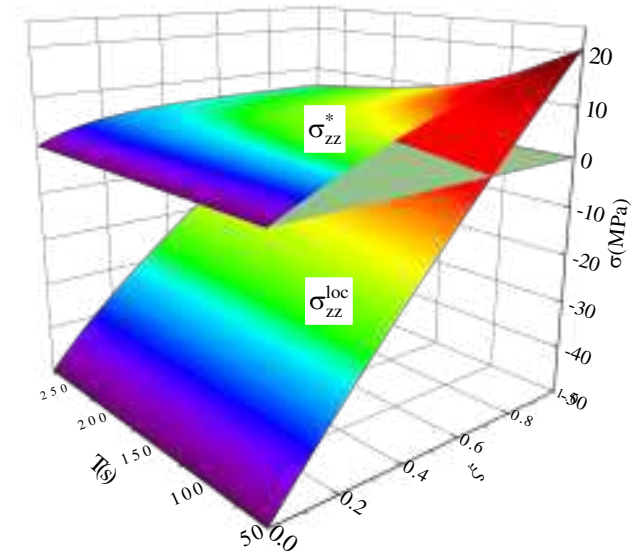

Fig.13 The law of stress change at the defect of the floor

\subsection{Distribution characteristics of floor unloading amount}

Based on the foregoing, the probability of floor unloading damage grows with the increase of the stress unloading amount. Therefore, the distribution characteristics of floor unloading amount in gob can be used to analyze the floor unloading damage. Let $\sigma$ and $\sigma^{\prime}$ are the stress states of the floor before and after unloading, respectively, and then the maximum and minimum principal stress unloading amounts are:

$$
\left.\begin{array}{l}
\xi_{1}=\frac{\sigma_{1}-\sigma_{1}^{\prime}}{\sigma_{1}} \\
\xi_{3}=\frac{\sigma_{3}-\sigma_{3}^{\prime}}{\sigma_{3}}
\end{array}\right\}
$$

According to the mechanical model in Fig. 8, the change law of unloading amount of stope floor after working face passes through is obtained, as shown in Fig. 14. The distribution characteristics of the maximum and minimum principal stress unloading amounts $\xi_{1}$ and $\xi_{3}$ are basically consistent, and both are greater than 0 , indicating that the floor is in the state of axial pressure and confining pressure relief, and the bidirectional unloading stress state increases the probability and complexity of unloading failure of the floor. Among them, the gob floor has the greatest unloading amount, while the residual coal pillar and the outer floor of the gob have the smallest one. $\xi_{1}$ and $\xi_{3}$ are symmetrically distributed around the coal pillar center, and $\xi_{3}$ is greater than $\xi_{1}$. Moreover, the unloading amount 
of the gob floor decreases with the increase of the floor depth, while the unloading amount of the coal pillar and the outer floor of the goaf increases with the increase of the depth.

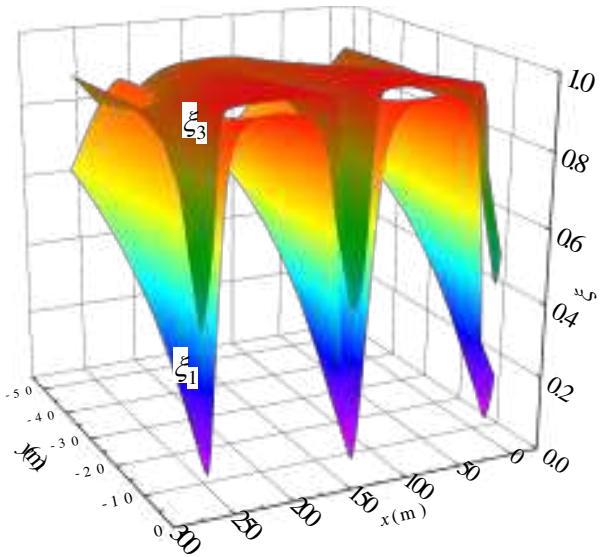

Fig.14 Distribution characteristics of principal stress unloading amount of goaf floor

The stress state of floor is composed of spherical stress tensor and deviatoric stress tensor, namely:

$$
\left[\begin{array}{ccc}
\sigma_{1} & 0 & 0 \\
0 & \sigma_{2} & 0 \\
0 & 0 & \sigma_{3}
\end{array}\right]=\left[\begin{array}{ccc}
\sigma_{m} & 0 & 0 \\
0 & \sigma_{m} & 0 \\
0 & 0 & \sigma_{m}
\end{array}\right]+\left[\begin{array}{ccc}
s_{1} & 0 & 0 \\
0 & s_{2} & 0 \\
0 & 0 & s_{3}
\end{array}\right] .
$$

In the equation, the first item on the right is the spherical stress tensor, $\sigma_{m}=\left(\sigma_{1}+\sigma_{2}+\sigma_{3}\right) / 3$; and the second item on the right is the deviatoric stress tensor, $s_{i}=\sigma_{i}-\sigma_{m}$. The spherical stress is closely related to the change of the unit volume, and the greater the spherical stress is, the higher the compression degree of the surrounding rock is; and the deviatoric stress is closely related to the change of the unit shape, but does not change the unit volume. Under the action of mining-induced pressure relief, the floor expands and deforms, and the spherical stress of surrounding rock mass decreases, extending from the gob to the deep surrounding rock of the floor, thus reducing the degree of rock pressure relief and the amount of spherical stress relief [32]. Therefore, the distribution characteristics of spherical stress relief amount can be used to reflect the expansion deformation characteristics of floor. Assuming that the spherical stress of the floor is $\sigma_{m}$ in the stage of abutment pressure disturbance, and $\sigma_{m}^{\prime}$ in the stage of gob compaction stability, and $\xi_{m}$ is to represent the unloading amount of the spherical stress, then:

$$
\xi_{m}=\frac{\sigma_{m}-\sigma_{m}^{\prime}}{\sigma_{m}}
$$

The mechanical model established in this paper is a plane model, and it is assumed that the floor is in the state of constant confining pressure, namely $\sigma_{2}=\sigma_{3}$. The spherical stress unloading amount of the floor was calculated based on Equation (21), as shown in Fig. 15. The spherical stress unloading amount of floor in gob is the largest, indicating that the gob has the greatest floor expansion deformation, and decreases gradually with the increase of buried depth; the spherical stress unloading amount of coal pillar and the outer floor of gob is the smallest, and increases gradually and tends to be stable with the increase of buried depth. 


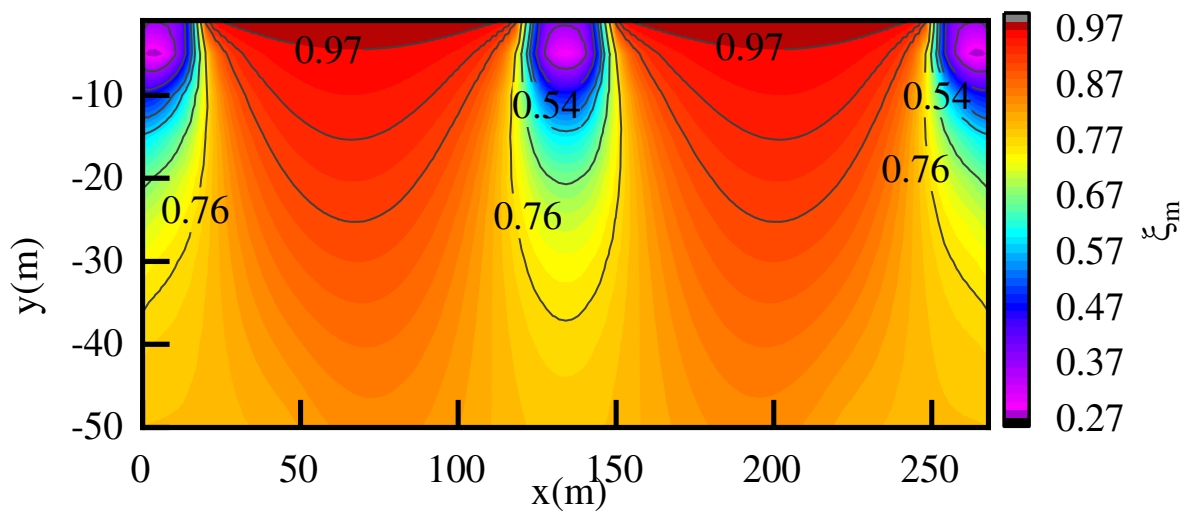

Fig.15 Distribution characteristics of spherical stress unloading amount

Based on the foregoing, in the process of working face advancement, the stope floor was in a pressurized state under the action of advance abutment pressure disturbance of the working face. However, due to the small principal stress difference, the floor did not suffer a large range of compressive shear failure. With the further advancement of the working face, when the floor in the working face entered into the free face, there was a strong rebound of high stress unloading in the gob floor, leading to a wide range of unloading expansion and deformation of the gob floor, and the shallow surrounding rock suffered unloading tensile failure. When the gob is compacted and stabilized, the principal stress difference between the residual coal pillar and the outer floor of the stope increases, leading to compression shear failure. Therefore, based on the above analysis, the zonal damage characteristics of stope floor were obtained, as shown in Fig. 16. According to the position of No. 11-1021 roadway, the surrounding rock near the coal pillar side of the roadway is the compressive shear failure zone, while the surrounding rock on the other side is the unloading tensile failure zone. As a result, the asymmetric distribution of the surrounding rock damage characteristics leads to the asymmetric failure phenomenon of the roadway.

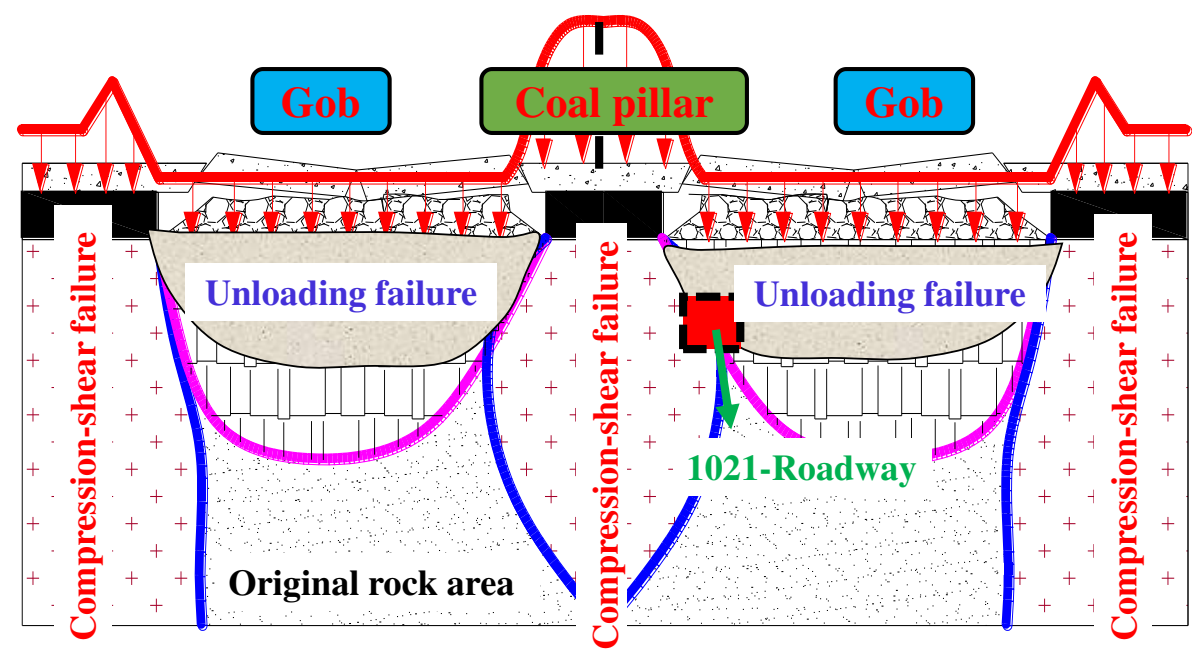

Fig.16 Partition failure characteristics of the floor

\section{Numerical simulation}

To verify the damage characteristics of stope floor and of surrounding rock of No. 11-1021 roadway, a numerical model of $320 \mathrm{~m} \times 220 \mathrm{~m} \times 145 \mathrm{~m}$ (length $\times$ width $\times$ height) was established based on FLAC ${ }^{3 \mathrm{D}}$ numerical calculation software. Horizontal constraints were imposed around the model and vertical constraints at the bottom of the model. The elastoplastic constitutive model and Mohr-Coulomb criterion were adopted. During excavation, coal pillars of $35 \mathrm{~m}$ wide were left at the side, front and rear of the working face, and step-by-step excavation was simulated. Based on the actual mechanical parameters of each rock strata in the East No. 1 Mining Area of Huipodi Coal Mine, the corresponding strength reduction [33][34] was realized by Hoek-Brown strength criterion to obtain the physical and mechanical parameters of each rock strata in numerical simulation, as shown in Table 2.

Tab.2 Rock physical and mechanical parameters table 


\begin{tabular}{ccccccc}
\hline Strata & $\begin{array}{c}\text { Density } \\
/\left({\left.\mathrm{kg} . \mathrm{cm}^{-3}\right)}\right.\end{array}$ & $\mathrm{K} / \mathrm{GPa}$ & $\mathrm{G} / \mathrm{GPa}$ & $\mathrm{c} / \mathrm{MPa}$ & $\sigma_{t} / \mathrm{MPa}$ & $\varphi^{/\left({ }^{\circ}\right)}$ \\
\hline Upper rock mass & 2460 & 6.3 & 5.1 & 3.1 & 0.3 & 28 \\
mudstone 1 & 2461 & 2.1 & 1.9 & 2 & 0.24 & 23 \\
Siltstone & 2680 & 5.1 & 3.8 & 2.1 & 0.25 & 26 \\
Limestone & 2800 & 3.5 & 2.5 & 2.2 & 0.26 & 26 \\
$10^{\#}$ coal seam & 1420 & 1.19 & 1 & 1.6 & 0.21 & 21 \\
$11^{\#}$ coal seam & 1423 & 2.5 & 1.72 & 1.9 & 0.21 & 21 \\
mudstone 2 & 2981 & 2.17 & 1 & 2 & 0.22 & 23 \\
Quartz sandstone & 2650 & 3.05 & 1.92 & 2.2 & 0.26 & 27 \\
Lower rock mass & 2680 & 6.3 & 5.1 & 3.1 & 0.3 & 28 \\
\hline
\end{tabular}

\subsection{Failure characteristics of stope floor}

The three-dimensional stress distribution characteristics of stope have an important corresponding relationship with the fissure distribution and evolution of roof and floor strata. According to the above analysis, the mining of the working face caused stress concentration and unloading in the surrounding rock. The unloading area gradually developed from the mining area of the coal seam to the depth of the overlying rock and the underlying rock, and the stress concentration appeared around the stress relief area. According to the principle of pressure arch, the high stress area in the three-dimensional state is actually a "stress concentration shell". Xie Guangxiang, Yang Ke et.al. [35][36] have proposed the concept of "macro stress shell" and analyzed in detail the factors that affect the shape of "macro stress shell". In this paper, based on the previous study results, the stress concentration area and stress relief area were distinguished from each other, the high-stress bundle surrounding rock whose spherical stress is obviously higher than the original rock stress was defined as the stress concentration shell, while the surrounding rock with spherical stress obviously lower than the original rock stress as the mining-induced stress relief body, and the partition failure characteristics of stope floor are analyzed. The spherical stress concentration shell and spherical stress relief body of the stope surrounding rock and the plastic zone unit of the floor were derived based on FISH language, as shown in Fig. 17.

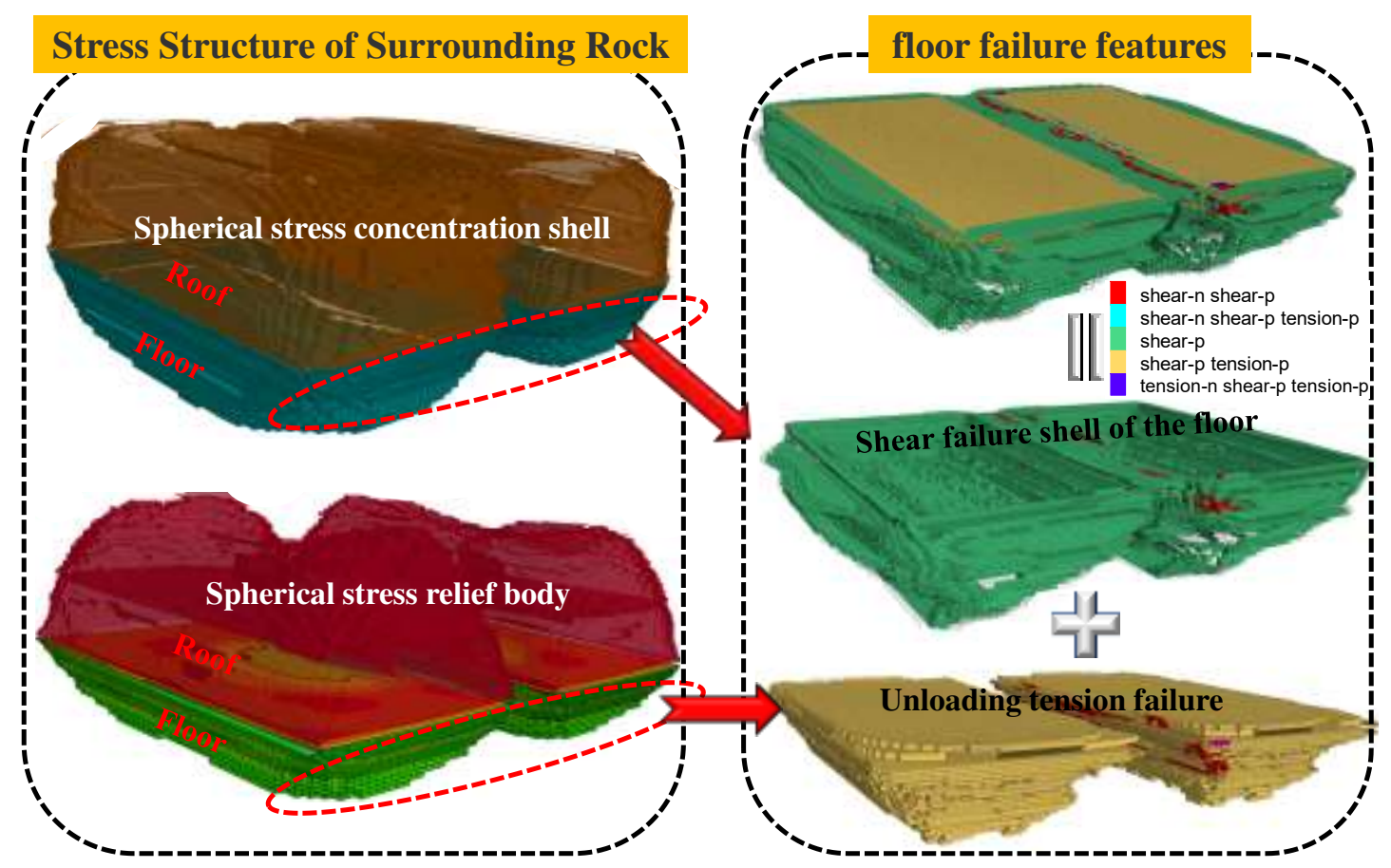

Fig.17 Comparison of surrounding rock stress structure and floor plastic element of stope

As can be seen from Fig. 17, there is a semicircular arched spherical stress concentration shell in the gob floor, and inside the spherical stress concentration shell is an inverted terraced spherical stress relief body. Compared with 
the distribution characteristics of the plastic zone of the floor, there is an inverted terraced tensile plastic zone in the gob floor. The shape and range of the tensile plastic zone correspond to the spherical stress relief body of floor, and there is an approximately semicircular arched shear failure shell outside the tensile plastic zone, and the shape and range of the shear failure shell correspond approximately to the spherical stress concentration shell of floor. This again indicates that the gob floor is dominated by unloading-induced tensile failure, while the rock mass outside the floor pressure relief body, namely the floor spherical stress concentration shell, is dominated by compressive shear failure, and the position of the floor shear failure shell is the maximum failure depth of the stope floor.

\subsection{Damage characteristics of floor roadway surrounding rock}

According to the continuum theory, the degree of plastic deformation can represent the degree of fracture development, so the ultrasonic wave in rock mass decreases with the increase of the degree of plastic deformation. Through fitting, the relationship between ultrasonic wave velocity and axial plastic strain was obtained as follows Error! Reference source not found.:

$$
v=0.95\left[1+\exp \left(-204 \varepsilon_{a}^{p}\right)\right]
$$

Where, $\varepsilon_{a}^{p}$ is the axial plastic strain of rock mass.

Axial plastic strain can reflect the degree of plastic deformation of rock mass under unidirectional loading. However, when the floor goes through the complex stress environment of excavation unloading and reverse loading, the axial plastic strain loses its function to reflect the deformation characteristics of floor. In this case, cumulative plastic strain can be used to reflect the deformation degree of stope floor. Based on the relevant data in literature [37], the following relationship is obtained by fitting the ultrasonic velocity and axial plastic strain:

$$
\varepsilon_{a}^{p}=1.5 \frac{1-\sin \psi}{\sqrt{3+\sin ^{2} \psi}} \xi_{n}
$$

Where, $\psi$ is dilatancy angle of rock mass $\left(^{\circ}\right)$, and $\xi_{n}$ represents cumulative plastic strain. By substituting Equation (23) into Equation (22), the relationship between ultrasonic wave velocity in the floor and cumulative plastic strain can be obtained.

The established ultrasonic wave velocity prediction model was embedded into FLAC $^{3 \mathrm{D}}$ numerical calculation software to obtain the distribution characteristics of ultrasonic wave velocity in the floor and the corresponding distribution of plastic zones, as shown in Fig. 18. Among them, the ultrasonic wave velocity in residual coal pillar floor is the highest, which is higher than that in the surrounding rock in elastic zone, while the ultrasonic wave velocity in gob floor is the lowest, which is lower than that in surrounding rock in elastic area. Both the coal pillar floor and the gob floor are in the plastic state, and the main reason for the great difference of ultrasonic wave velocity in the two areas is the different modes of floor failure. The high stress concentration in the coal pillar floor causes compressive shear failure of the rock mass, and the fissures are mainly closed under compression. Moreover, the high stress concentration makes the floor in a state of compression, leading to an increase of the rock density, which is conducive to the propagation of ultrasonic wave. The gob floor is mainly in the unloading state, the unloading tension-induced fissures are usually wider than compressive shear-induced ones, so the former fissures have a larger volume. Moreover, the gob floor is in the state of expansion and deformation, so the rock density is small, which is not conducive to the propagation of ultrasonic wave. The excavation of No. 11-1021 roadway caused secondary unloading effect on the surrounding rocks, which further reduced the ultrasonic wave velocity in the surrounding rock. 


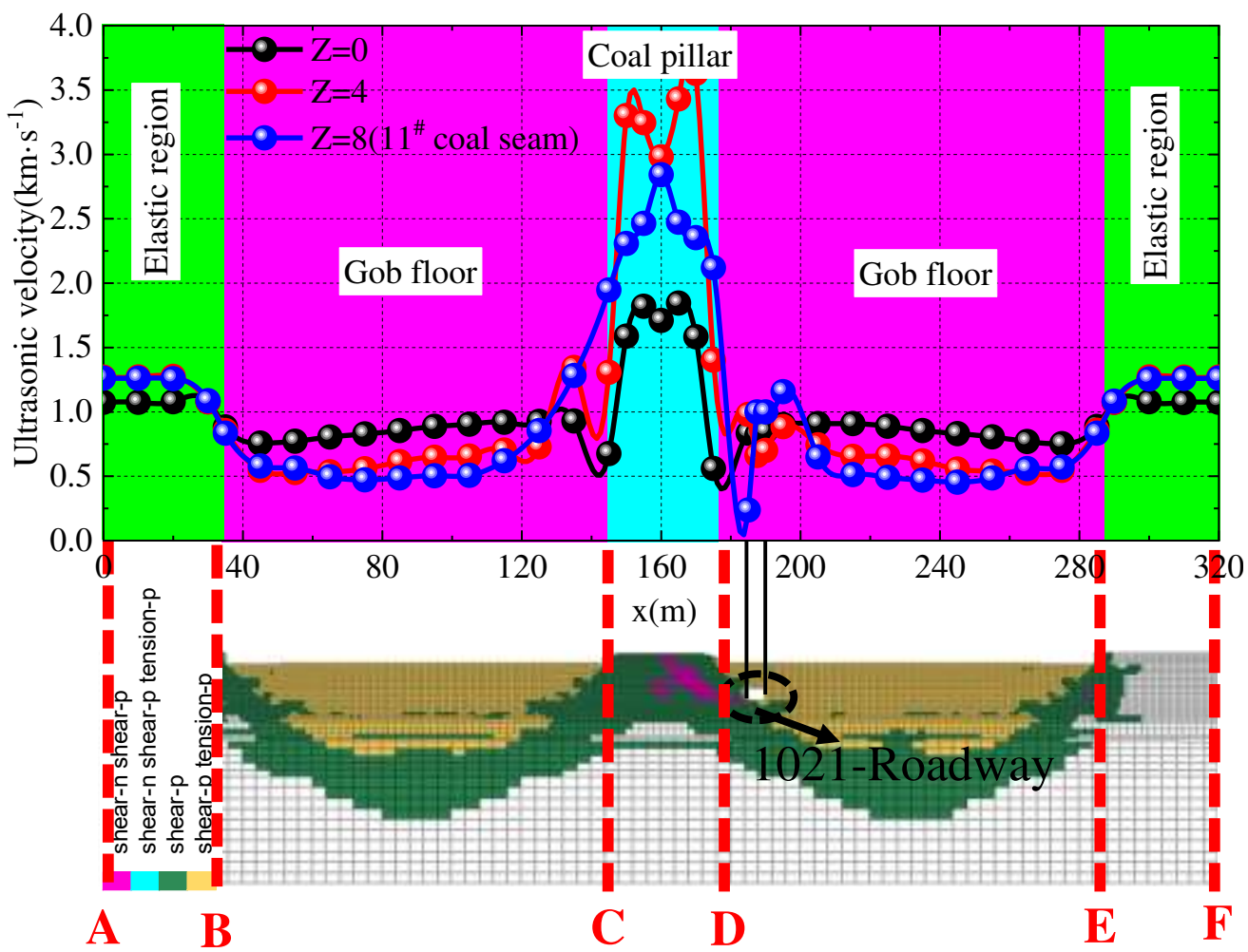

Fig.18 The distribution of ultrasonic velocity and plastic zone of stope floor

The displacements of surrounding rock and ultrasonic propagation velocity in No. 11-1021 roadway are shown in Fig. 19. It can be seen from Fig. 19 that the floor heaving amount, which is asymmetrically distributed, is smaller near the residual coal pillar side than that of the other side, and the ultrasonic wave velocity in both sides of the roadway floor is greater than that in the middle, indicating that the fissure density in the middle of the roadway floor is larger; the roof subsidence, which is also asymmetrically distributed, is greater near the residual coal pillar side than that of the other side, and the ultrasonic wave velocity in both sides of the roof is greater than that in the middle, indicating that the fissure density in the middle of the roof is larger; the convergence, which is asymmetrically distributed on the left and right ribs of the roadway, is greater in the roadway rib near the residual coal pillar than that of the other rib, and the ultrasonic wave velocity in the roadway rib near the residual coal pillar is greater than that in the other rib, indicating that surrounding rock of roadway rib near the residual coal pillar has poorer integrity, which is consistent with the field observation results as shown in Fig. 7.

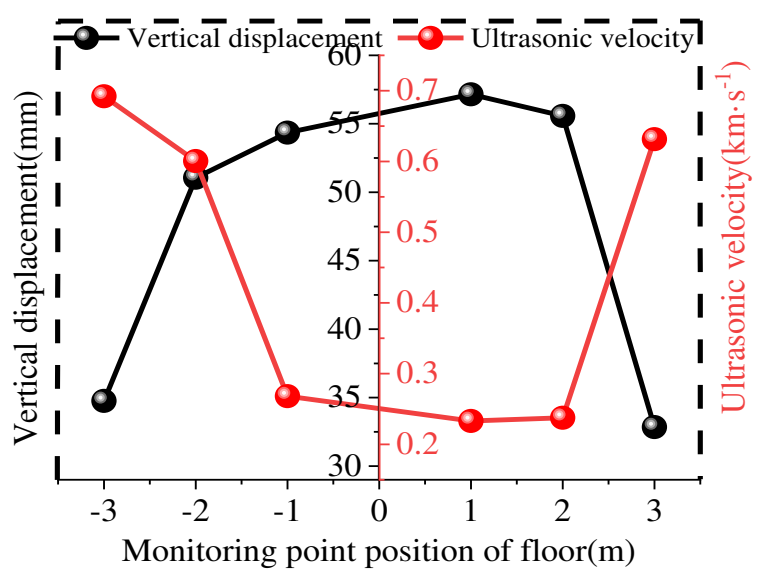

(a)floor

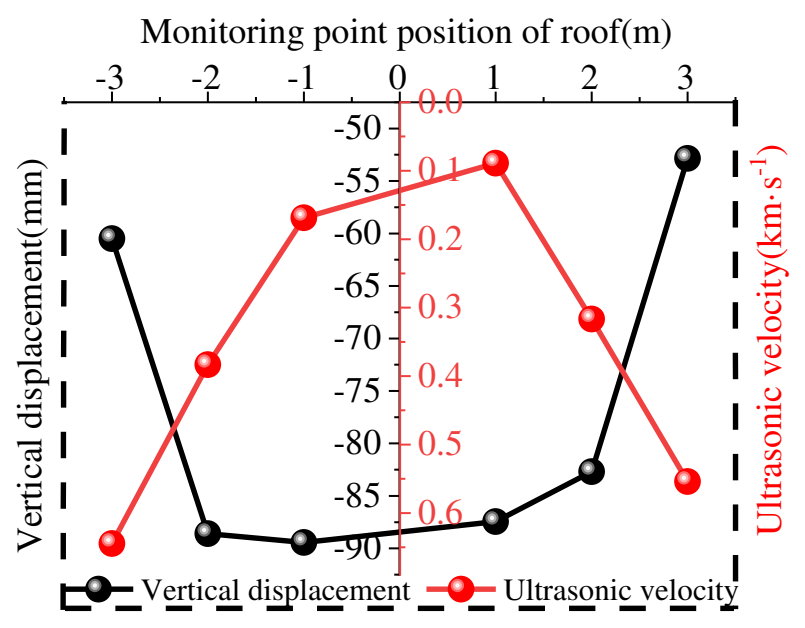

(b)roof 


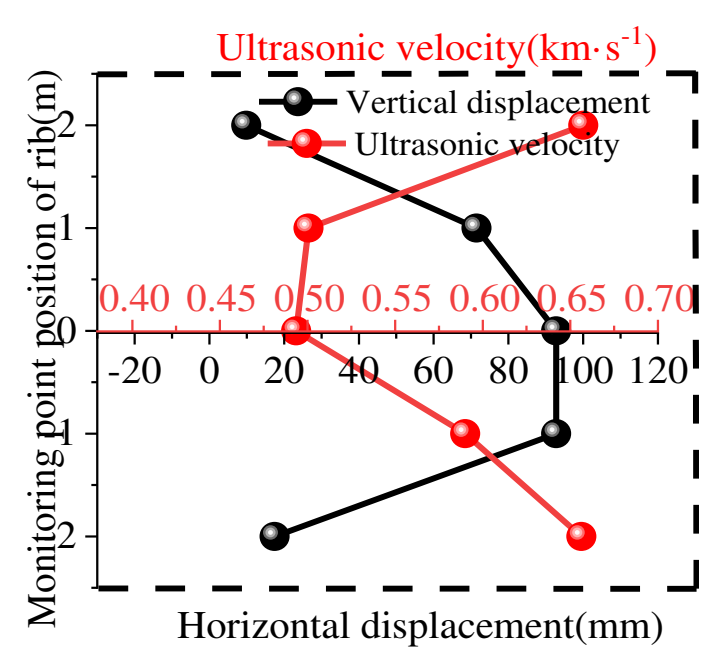

(c) the rib near the coal pillar

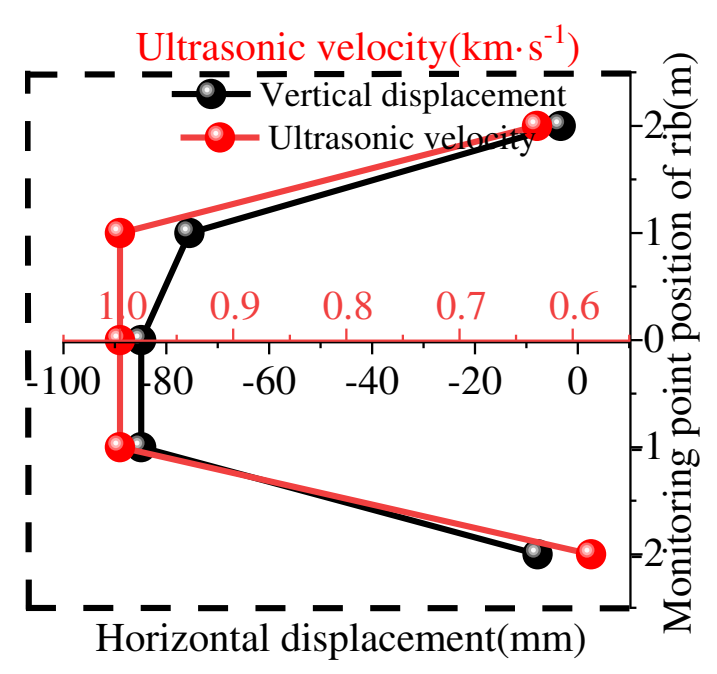

(d) the rib away from the coal pillar

Fig.19 11-1021 Roadway surrounding rock displacement and ultrasonic propagation characteristics

To sum up, No. 11-1021 roadway is close to the rock with compressive shear failure on one side and close to the rock with unloading tensile failure on the other side, resulting in the asymmetric failure characteristics of the surrounding rock as shown in Fig. 4. When the roadway is excavated, the roadway floor far away from the residual coal pillar side is close to the unloading tensile failure area, so it suffers more serious unloading damage, and the floor heave is larger under the high stress extrusion of the residual coal pillar and the rheological action of the rock mass. Due to the obvious stress concentration in the floor rock of residual coal pillar (compressive shear failure zone), the secondary compression shear failure is easy to occur after roadway excavation on the roof near the residual coal pillar and the rock mass of roadway rib. The asymmetric failure mechanism of surrounding rock of No. 11-1021 roadway is shown as Fig.20.

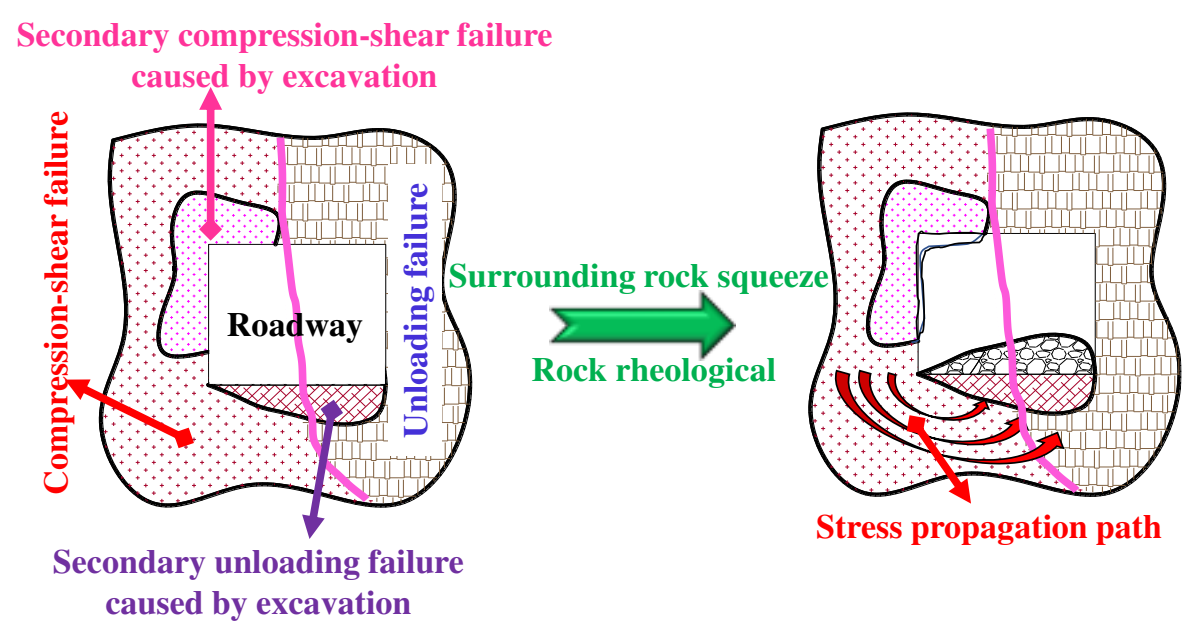

Fig.20 Schematic diagram of asymmetric failure process of surrounding rock in roadway

\section{Roadway support strategy}

Based on the above study on the asymmetric deformation mechanism of surrounding rock in No. 11-1021 roadway, a more reasonable support strategy for the roadway was proposed, which provides references for the roadway support and stability maintenance in the later stage of the mine. Asymmetric support technology designed according to the deformation and failure characteristics of No. 11-1021 roadway is shown in Fig. 21. 


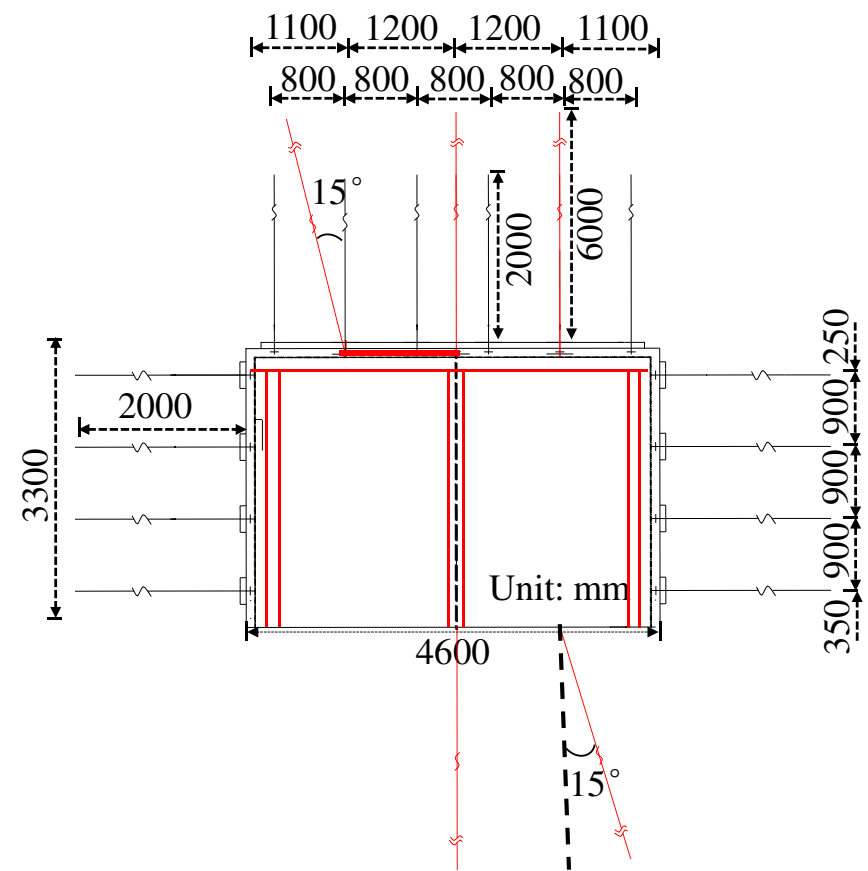

(a) Roadway support profile
W-type steel band Diamond-shaped net

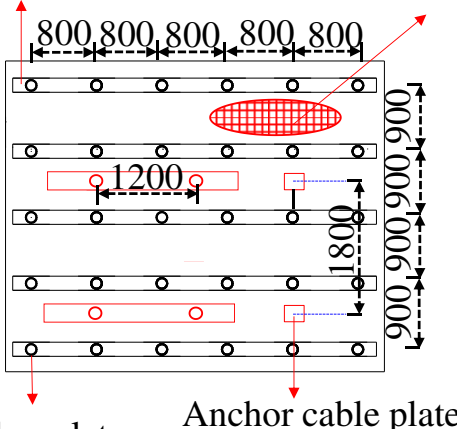

Anchor plate

(b) Roadway roof support plan

Fig.21 11-1021 Roadway support plan

(1) Adjustment of roof support parameters

According to the asymmetric deformation characteristics of the roof of No. 11-1021 roadway, with the engineering analogy method, an asymmetric support technology characterized by parallel arrangement of W-type steel band-based simple truss anchor cable and single anchor cable was proposed. The simple truss anchor cable mainly provides key support for the roof side with great deformation, with the anchor cable span of $1200 \mathrm{~mm}$, row spacing of $1800 \mathrm{~mm}$. The anchor cable still adopts high strength elastic relaxation steel strand with a diameter of $18.9 \mathrm{~mm}$ and length of $6000 \mathrm{~mm}$, and the single anchor cables are still arranged vertically according to the original support parameters. This support technology has the advantages of prominence to the key points, combination of inflexibility and yielding, combination of points and lines, balanced bearing capacity, etc., whose rationality and effectiveness has been verified in existing engineering sites [38].

(2) Design of floor support parameters

The support strategy for the floor of No. 11-1021 roadway has been adjusted from no support to the asymmetric support based on parallel arrangement of single anchor cables. Based on the foregoing, the floor heaving of the side of No. 11-1021 roadway far away from the residual coal pillar is large, and the floor of this side is dominated by unloading-induced tensile damage, so the rock here has poor integrity. Therefore, a single anchor cable is slantways set $1100 \mathrm{~mm}$ away from the side roadway. Moreover, as the ultrasonic wave velocity in the middle of the roadway floor is smaller than that on the two sides, to ensure the stability of the middle part of the roadway floor, a single vertical anchor cable is added in the middle part of the roadway floor for support, with the row spacing of $1800 \mathrm{~mm}$.

The above-mentioned support parameters adjusted according to the asymmetric deformation characteristics of surrounding rock of No. 11-1021 roadway are reasonable to a certain extent, and provide a reference for the reasonable support of the roadway. In the next stage, relevant engineering tests will be carried out in some key areas of the roadway.

\section{Discussion and analysis}

After the working face is pushed, the fissures of gob floor are fully developed under the disturbance of mininginduced stress, which makes floor rock have obvious anisotropic characteristics. The relationship between the ultimate bearing capacity $\boldsymbol{R}_{c}$ of fractured rock and the fracture direction is shown in Fig. 22 [39]. Where, $\gamma$ is the angle between the maximum principal stress and the micro-fissure surface; and $\varphi_{f}$ represents the friction angle of micro-fissures. 


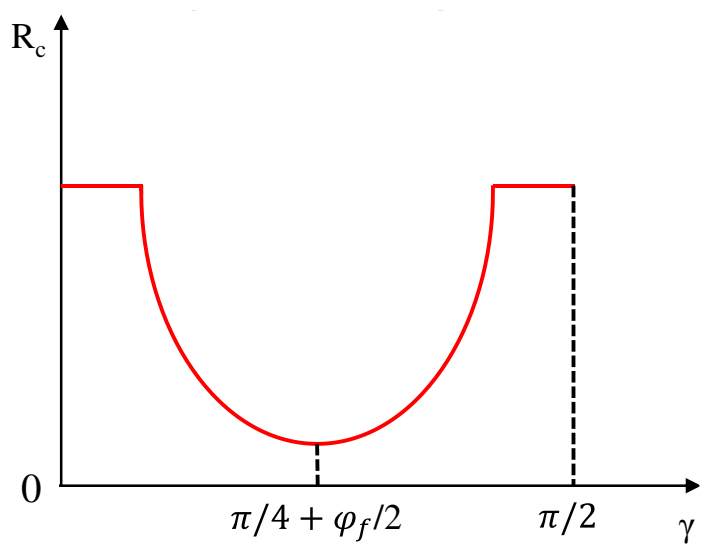

Fig.22 Bearing capacity of fractured rock

With the increase of the angle $\gamma$, the bearing capacity of fractured rock first decreases and then increases, and when $\gamma=\pi / 4+\varphi_{f} / 2$, it is the worst. Therefore, the stability of stope floor is not only affected by stress concentration and excavation unloading, but also by the rotation of stress direction. Under the mining disturbance, if the principal stress direction of the floor deflects, the floor stability will show different evolution characteristics with different rotational trajectories of the principal stress direction. Hence, analyzing the principal stress rotation characteristics of stope floor can provide stress field conditions for the research on the development characteristics of floor fracture field. Before mining, the maximum principal stress of the floor is parallel to the $\mathrm{Z}$ axis, and the minimum principal stress parallel to the $\mathrm{X}$ axis. After mining, the principal stress of the floor rotates, and the stereographic projection of the principal stress of the surrounding rock of the floor at different depths is shown in Fig. 23. In the figure, points A F correspond to the positions in Fig. 18, and the arrow indicates the advancing direction of the working face. The principal stress of floor rock rotates mainly in the vertical plane perpendicular to the advancing direction of working face, while the principal stress of rock in the shallow part of floor rotates in the vertical plane parallel to the advancing direction of working face. From point $\mathrm{A}$ to point $\mathrm{B}$ (or $\mathrm{F}$ to $\mathrm{E}$ ), the principal stress of the floor rotates toward the direction of the coal pillar; from point $B$ to point $C$ (or $E$ to $D$ ), the maximum principal stress reverses, while the minimum principal stress continues to rotate toward the coal pillar; and from both sides (points $\mathrm{C}$ and $\mathrm{D}$ ) to the middle of the pillar floor, the maximum principal stress rotates toward the vertical direction, while the minimum principal stress rotates toward the horizontal direction. In general, the minimum principal stress in the stereographic projection is more dispersed and its distribution range is wider, indicating a larger deflection of the minimum principal stress of the floor. From the above analysis, it can be seen that the principal stress deflection directions of different zones of the stope floor are different. Since the direction of fracture expansion is greatly affected by the direction of the principal stress [40][41], the author believes that the fracture field of stope floor should also show obvious zoning characteristics, and will also carry out corresponding research on this point in the future.

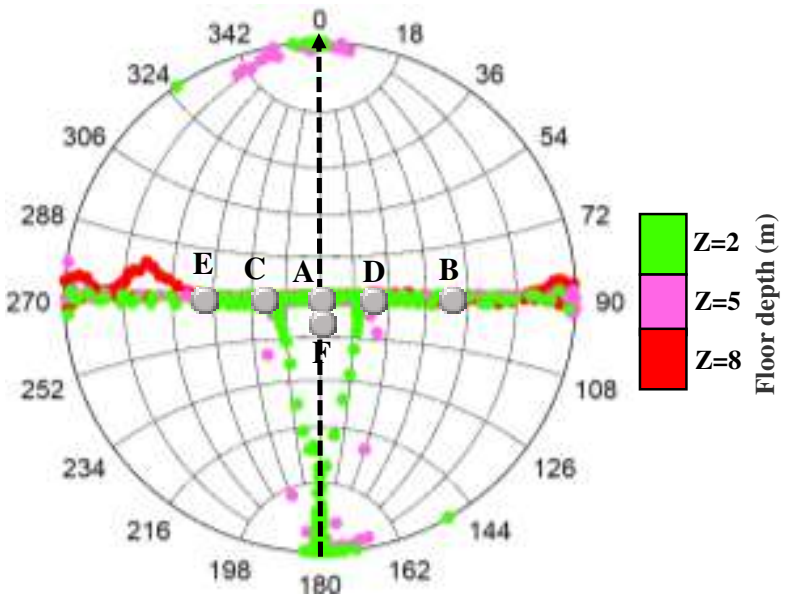

(a)maximum principal stress

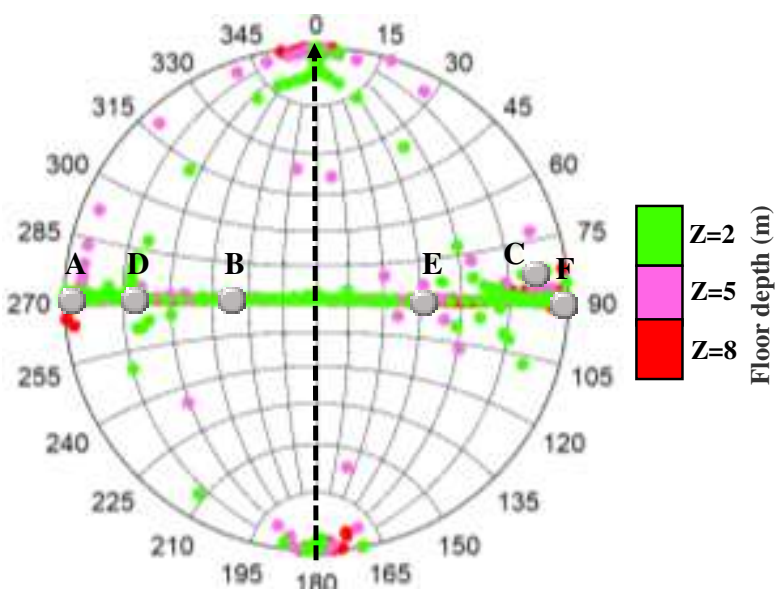

(b) minimum principal stress

Fig.23 Principal stress deflection characteristics of the floor 


\section{Conclusions}

In the context of the engineering background of Huipodi Coal Mine, this paper comprehensively analyzed the failure mechanism and zonal failure characteristics of stope floor by means of field observation, theoretical analysis and numerical simulation. Based on this, the asymmetric failure mechanism of surrounding rock of No. 11-1021 roadway was obtained and the corresponding support countermeasures were put forward. The main conclusions were obtained as follows:

(1) Under the influence of the residual coal pillar in the upper coal seam, the floor roadway rib near the residual coal pillar has lower ultrasonic wave velocity than the other rib, with more developed fissures. The deflection is larger in the middle of the roadway roof and the tensile failure is the dominant one, and as a result, the ultrasonic wave velocity in the middle of the roadway roof is lower than that on both sides.

(2) Under the advance abutment pressure, the maximum principal stress and minimum principal stress of stope floor are in the state of high value, and there was no large-scale failure in stope floor. In the compaction stability stage, the floor undergoes unloading, leading to the change of stress state. A large range of compressive shear failure was found in the residual pillar floor, and a small range of compressive shear failure in the outer floor of the stope. There is no compressive shear failure in the gob floor, but the mining-induced unloading causes a tensile stress at the internal defects of the floor rock, and due to the maximum unloading amount of the gob floor, the gob floor is dominated by unloading-induced tensile failure.

(3)There is a semicircular arch spherical stress concentrated shell and inverted terraced spherical stress relief body in the gob floor. The shape and range of tensile plastic zone of the gob floor correspond to the spherical stress relief body, and the shape and range of shear failure zone of the floor correspond to the spherical stress concentrated shell. The coal pillar floor is dominated by compression-induced closed cracks, while the gob floor is dominated by expansion deformation and unloading-induced tensile cracks, which leads to the lower ultrasonic wave velocity of the gob floor than that of the coal pillar floor.

(4) One side of the surrounding rock of No. 11-1021 roadway is close to the rock mass with compressive shear damage and the other side close to the rock mass with unloading-induced tensile damage, which is the main reason for the asymmetric failure of the roadway. Based on the asymmetric failure mechanism of the roadway, an asymmetric support technology characterized by parallel arrangement of W-type steel band-based simple truss anchor cable and single anchor cable was proposed for the roof, and an asymmetric support technology characterized by parallel arrangement of single anchor cables for the floor.

\section{Acknowledgments}

Authors gratefully acknowledge the financial support of The Open Fund Project of state Key Laboratory of Mining Response and Disaster Prevention and Control in Deep Coal Mines (SKLMRDPC19KF01), National Science Fund subsidized project (51474220) and Basic scientific research project of the CPC Central Committee (2021YJSNY27).

\section{Declaration of interest statement}

No potential conflict of interest is reported by the authors.

\section{References}

[1]. Liu B, Yue Z Q, Tham L G. Analytical design method for a truss-bolt system for reinforcement of fractured coal mine roofs-illustrated with a case study[J]. International Journal of Rock Mechanics and Mining 
Sciences, 2005, 42(2):195-189.

[2]. Wang Xufeng, Qin Dongdong, Zhang Dongsheng, et al. Evolution characteristics of overburden strata structure for ultra-thick coal seam multi-layer mining in Xinjiang East Junggar Basin[J]. Energies, 2019, 12(2): 332-345.

[3]. Wang Wei, Cheng Yuanping, Wang Haifeng, et al. Fracture failure analysis of hard-thick sandstone roof and its controlling effect on gas emission in underground ultra-thick coal extraction [J]. Engineering Failure Analysis, 2015, 54: 150-162.

[4]. Meng X, Liu W, Zhao J, et al. In situ investigation and numerical simulation of the failure depth of an inclined coal seam floor: a case study[J]. Mine Water and the Environment, 2019, 38(3): 686-694.

[5]. Santos CF, Bieniawski ZT. Floor design in underground coalmines[J]. Rock Mechanics and Rock Engineering, 1989, 22(4): 249-271.

[6]. Zhou W, Zhang P, Wu R, et al. Dynamic monitoring the deformation and failure of extra-thick coal seam floor in deep mining[J]. Journal of Applied Geophysics, 2019, 163: 132-138.

[7]. Santos CF, Bieniawski ZT. Floor design in underground mines[J]. Rock Mechanics and Rock Engineering, 1989, 22(4): 249-271.

[8]. Ghasemi E, Ataei M, Shahriar K, et al. Assessment of roof fall risk during retreat mining in room and pillar coal mines[J]. International Journal of Rock Mechanics and Mining Sciences, 2012, 54: 80-89.

[9]. Mironenko V, Strelsky F. Hydrogeomechanical problems in mining[J]. Mine Water and the Environment, 1993, 12(1): 35-40.

[10].LIU Tianquan. Influence of mining activities on mine rock mass and control engineering[J]. Journal of China Coal Society, 1995(01): 1-5.

[11].WANG Lianguo, HAN Meng, WANG Zhansheng, et al. Stress distribution and damage law of mining floor[J]. Journal of Mining \& Safety Engineering, 2013, 30(3): 317-322.

[12].LUO Feng, CAO Shugang, LI Guodong, et al. Temporal-spatial variation characteristics of strain in coal seam floor during downward and layer-by-layer mining in ultra-distance coal seams. [J]. Journal of Mining \& Safety Engineering, 2018, 35(05): 997-1004+1013.

[13].GUO Wenbing, LIU Mingju, LI Huamin, et al. The optics-elastic simulation study on the stress of the surrounding rock of the coal face in multi-coal seam mining[J]. Journal of China Coal Society, 2001, 26(1): 8-12.

[14].GUO Wenbing, ZHAO Gaobo, LOU Gaozhong, et al. A new method of predicting the height of the fractured water-conducting zone due to high-intensity longwall coal mining in china[J]. Rock Mechanics and Rock Engineering,2019,52:2789-2802.

[15].FANG Xinqiu, GUO Minjiang, LV Zhiqiang. Instability mechanism and prevention of roadway under Close-distance seam group mining[J]. Chinese Journal of Rock Mechanics and Engineering, 2009, 28(10): 059-2067.

[16].TU Shihao, WANG Fangtian, DOU Fengjin, et al. Fully mechanized top-coal caving underground stress at gateways under barrier pillars of an upper coal seam[J]. Journal of China University of Mining \& Technology, 2010, 35(2):191-193.

[17].ZHANG C, TU S H, ZHAO Y X. Compaction characteristics of the caving zone in a longwall goaf a review[J]. Environmental Earth Sciences, 2019, 78(1): $27-46$.

[18].LU Shiliang, JIANG Yaodong, SUN Yonglian. The selection of vertical distance $Z$ between roadway and its upper coal seam[J]. Journal of China University of Mining \& Technology, 1993(1): 4-10.

[19].Zhang R, Jiang ZQ, Zhou HY, et al. Groundwater outbursts from faults above a confined aquifer in the coal mining. Nat Hazards. 2014;71(3):1861-1872.

[20]. Liu WT, Zhao JY, Li Q. A MHC-NF coupling model for water inrush from collapse columns and its numerical simulation. Geotech Geol Eng. 2018;26:2637-2647.

[21].LAU J S O, CHANDLER N A. Innovative laboratory testing[J] International Journal of Rock Mechanics 
and Mining Sciences,2004,41(8):1 427-1 445.

[22].Xiao-Ming S, Feng C, Man-Chao H, et al. Physical modeling of floor heave for the deep-buried roadway excavated in ten degree inclined strata using infrared thermal imaging technology[J]. Tunnelling and Underground Space Technology, 2017, 63:228-243.

[23].Chen H, Qi C, Efremidis G, et al. Gradient elasticity and size effect for the borehole problem[J]. Acta Mechanica, 2018, 229(3):1-14.

[24].KERN H, SCHENK V. A model of velocity structure beneath Calabria, southern Italy, based on laboratory data[J]. Earth and Planetary Science Letters, 1988, 87(3): 325-337.

[25].FAN Xiufeng, JIAN Wenbin. Experimental research on fatigue characteristics of sandstone using ultrasonic wave velocity method[J]. Chinese Journal of Rock Mechanics and Engineering, 2008, 27(3): $557-563$.

[26].ZHU Jinsong, SONG Yupu. Research on fatigue damage of concrete under biaxial compressive loading using ultrasonic velocity method[J]. Chinese Journal of Rock Mechanics and Engineering, 2004, 23(13): 2230-2 234.

[27].QIAN Minggao, SHI Pingwu, XU Jialin. Mine pressure and rock formation control[M]. Xuzhou: China University of Mining \& Technology Press, 2010:222-224.

[28].Zhengzhao Liang, Wencheng Song, Weitao Liu. Theoretical models for simulating the failure range and stability of inclined floor strata induced by mining and hydraulic pressure[J].International Journal of Rock Mechanics and Mining Sciences, 2020, 132(132)

[29].Lu Haifeng, Liang Xiuyu, Shen Nan, et al. Study on the stability of the coal seam floor above a confined aquifer using the structural system reliability method[J]. Geofluids, 2018, 2018:1-15.

[30]. Xu ZL. Concise Tutorial on Elasticity. Beijing: Higher Education Press; 2002. in Chinese.

[31].RODIONOV V N, SIZOV I A, TSVETKOV V M. Elements of geomechanics[M]. Moscow: Nedra, 1986.

[32].ZHANG Guangchao, LIANG Saijiang, TAN Yunliang, et al. Numerical modeling for longwall pillar design: a case study from a typical longwall panel in China[J]. Journal of Geophysics and Engineering. 2018, 15(1): 121-134.

[33].HOEK E, CARRANZA T, CORKUM B. Hoek-Brown criterion-2002 edition[C]// Proceedings of NARMS-TAC Conference. Toronto: [s. n.], 2002: $267-273$.

[34].Ramamurthy T. A geo-engineering classification for rocks and rock masses[J]. International Journal of Rock Mechanics \& Mining Sciences, 2004, 41: 89-101.

[35].XIE Guangxiang, CHANG Jucai, YANG Ke. Investigations into stress shell characteristics of surrounding rock in fully mechanized top-coal caving face[J]. International Journal of Rock Mechanics and Mining Sciences, 2009, 46 (1) :172-181.

[36].XIE Guangxiang, YANG Ke.Study of macro stress shell evolving characteristics of rock surrounding face[J]. Chinese Journal of Rock Mechanics and Engineering, 2010, 29 (Sup 1) :2676-2680.

[37].Zhao Hongbao, Wang Tao, Su Poyi, et al. Study on the Mechanism of Asymmetric Deformation of the Floor of Mining Roadway in Huipodi Coal Mine[J]. Journal of china University of Mining \& Technology, 2020, 49(02): 227-237.

[38]. YIN Shuaifeng, CHENG Genyin, HE Fulian, et al. An asymmetric support technique for fully-mechanized coal roadway nearby narrow pillar based on the fracture position analysis in basic roof[J]. Chinese Journal of Rock Mechanics and Engineering, 2016, 35(Supp.1): 3162-3174.

[39].JAEGER J C, COOK NGW, ZIMMERMAN RW. Fundamentals of rock mechanics[M]. Malden: Blackwell Publishing, 2007.

[40].Wang J, Wang Z, Yang S. A coupled macro- and meso-mechanical model for heterogeneous coal[J]. International Journal of Rock Mechanics \& Mining Sciences, 2017, 94: 64-81.

[41]. Yongzheng Wu, Fuqiang Gao, Jinyu Chen, et al. Experimental study on the performance of rock bolts in coal burst-prone mines [J]. Rock Mechanics and Rock Engineering, 2019, 52(10): 3959-3970. 
